\title{
Seismic Performance of Exterior RC Beam-Column Joints Retrofitted using Various Retrofit Solutions
}

\author{
Gia Toai Truong, Ngoc Hieu Dinh, Jong-Chan Kim, and Kyoung-Kyu Choi*
}

(Received October 15, 2016, Accepted May 8, 2017, Published online September 12, 2017)

\begin{abstract}
Beam-column joints in existing concrete buildings might not satisfy the design requirements for seismic reinforcement details specified in current seismic design codes. Thus, in this study, various retrofit solutions for existing exterior beam-column joints with non-seismic details were developed: head re-bars anchoring, carbon fiber reinforced polymer (CFRP) wrapping, haunch retrofit element, and steel jacketing with various shapes and sizes. To investigate the seismic performance of exterior joints strengthened with the proposed retrofit solutions, seven half-scale exterior reinforced concrete beam-column joints including one control specimen and six retrofitted specimens were fabricated and tested under cyclic loading simulating earthquake loading. The test results showed that the proposed retrofit solutions could partially enhance the seismic capacity of the beam-column joints: steel jackets could increase deformation and load-carrying capacities; steel haunch elements could increase the load-carrying capacity, stiffness, and dissipated energy; and head re-bar anchoring and CFRP wrapping did not significantly effect on the seismic capacity of the beam-column joints.
\end{abstract}

Keywords: seismic retrofit, exterior concrete beam-column joints, head re-bars, carbon fiber reinforced polymers, haunches, steel jackets.

\section{Introduction}

The moment resisting frame is one of the most widely used structure systems in reinforced concrete (RC) buildings subjected to gravity and/or seismic loading. From a structural point of view, while beam-column joints that connect main structural members (i.e., beams and columns) are the weakest components, they are the most complicated components as they transfer internal forces between the structural members. In many developing countries (e.g. Korea), existing concrete buildings constructed before the 1980s were designed to resist mainly gravity loads. Thus, in the past, many reinforced concrete buildings in developing countries collapsed during severe earthquakes (including those in Costa Rica in 1991 (Al-Tarazi 2000), in Nicaragua in 1992 (Kanamori and Kikuchi 1993), and in Egypt in 1995 (Suarez et al. 1995)). It was found that in many cases the collapse of such reinforced concrete buildings was caused by inadequate reinforcement details of beam-column joints.

According to a previous investigation (the Korea National Emergency Management Agency 2011) in Korea, concrete beam-column joints designed without consideration of earthquake load have certain material and geometrical

School of Architecture, Soongsil University, 369 Sangdoro, Dongjak-gu, Seoul 06978, South Korea.

*Corresponding Author; E-mail: kkchoi@ssu.ac.kr

Copyright (c) The Author(s) 2017. This article is an open access publication characteristics: low concrete strength; plain steel re-bars; inadequate or no transverse reinforcement in beam-column joints; and insufficient anchorage detailing leading to lack of concrete confinement (Santersiero and Masi 2015; Pampanin et al. 2002; Engindeniz et al. 2005). When such concrete buildings are subjected to earthquake loading, the beamcolumn joints (in particular, the corner and exterior joints) could fail in brittle manner, which might trigger partial or entire collapse of the buildings (Rashidian et al. 2016; Petrone et al. 2016). Thus, the rehabilitation of such beamcolumn joints is a prerequisite to resist seismic loads.

To develop retrofit techniques for external beam-column joints with non-seismic details, a number of studies have been performed. Shafaei et al. (2014) strengthened four nonseismically detailed RC beam-column joints with steel angles, which were mounted using prestressed cross-ties. With the use of the retrofit technique, slippage was prevented by increasing the joint area of the beam bottom reinforcement, the plastic hinge was relocated far from the column face, and the shear strength, stiffness, energy dissipated, and ductility capacity were also significantly increased up to 50 , 120,220 , and $220 \%$, respectively.

El-Amoury and Ghobarah (2002) investigated the seismic performance of the joints retrofitted with glass fiber-reinforced polymers (GFRP). The proposed rehabilitation schemes consist of two systems: the first system is used for upgrading the shear strength of the joint with two U-shaped GFRP layers, and the second system is used for upgrading the bond-slip of the steel bars. The use of GFRP jacketing significantly enhanced the ductility and the load-carrying 
capacity of the rehabilitated joints $(52 \%$ higher than that of non-retrofitted joints). The brittle joint shear failure of the retrofitted specimens was eliminated, the bonding between concrete and beam top reinforcement was improved, the stiffness degradation of the joints was reduced, and the dissipated energy increased by up to six times compared to that of non-retrofitted joints.

Del Vecchio et al. (2014) also investigated the seismic performance of exterior RC beam-column joints retrofitted with fiber-reinforced polymers (FRP) through an experimental program carried out on six full-scale test specimens. From the test results, it was found that the observed maximum strain of FRP (approximately 1.0\%) was larger than $0.4 \%$ as design maximum strain and the amount of FRP joint reinforcement significantly influenced on joint panel deformations. Based on such test results, analytical models were also developed to predict the shear strength of beam-column joints having light reinforcement details retrofitted with FRP systems (Del Vecchio et al. 2015; Pantazopoulou et al. 2016). In addition, Ronagh and Baji (2014) and Del Vecchio et al. (2016) simulated the shear behaviour of RC beamcolumn joints using finite element method (FEM). In the analysis by Del Vecchio et al. (2016), the anchorage effect of beam bars and the shear contribution of the FRP strengthening system were delicately accounted for, and the analysis results showed a good agreement with the test results in terms of strength, global deformation, crack pattern, strength and stiffness degradation, and pinching.

Pampanin et al. (2006) experimentally investigated the effectiveness of various haunch retrofit solutions on the seismic response of the reinforced concrete beam-column joints. The haunch elements were used including diagonal axial elements and they were hinged or welded to the steel plates at both ends to form haunch elements. These haunch elements were connected to the beams and columns by using two partially prestressed external rods along with two anchors, which were directly fastened to the beams and columns. The shear strength and ductility capacity of the retrofitted joints were significantly improved, and the failure mode was changed to flexural hinging in the beam.

The failure modes of the beam-column joints were investigated and classified into three types according to the study by Lee et al. (2009). In Fig. 1, J-failure refers to the

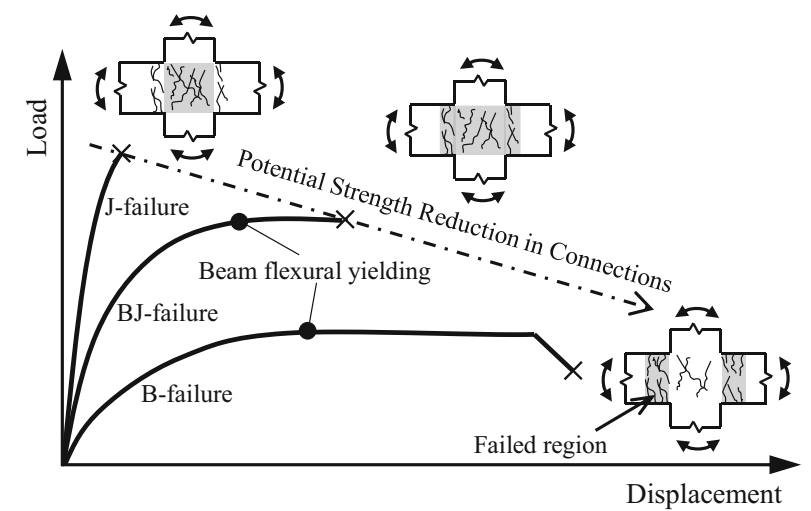

Fig. 1 Types of failure modes of the beam-column joints (Lee et al. 2009). connection failure before plastic hinges formed at the ends of adjacent beams, which is associated with low displacement and ductility capacity. BJ-failure refers to the connection failure after the plastic hinges develop at both ends of adjacent beams, and B-failure refers to beam failure in the plastic hinge regions while beam-column connections remain elastic. Compared to J-failure, the BJ- and B-failures are more ductile modes, since BJ- and B-failures involve beam yielding.

Judging from the research results mentioned above and other literatures (Campione et al. 2015; Ruiz-Pinilla et al. 2014; Bansal et al. 2016; Tsonos 2010; Sharma et al. 2014), it was obvious that such developed retrofit techniques were effective in enhancing the seismic performance of exterior beam-column joints. However, the most significant disadvantage of the previous retrofit techniques was the lack of practicability. In some cases, the surfaces of the joints parallel to the beam direction cannot be covered with retrofit materials because of the existence of beams in orthogonal directions. The floor space in the upper story could be considerably minimized because of the retrofit materials; the durability can be weakened because of the holes drilled through the beams and columns, and the use of concrete jacketing could increase the dimensions and weight of the structures. Thus, the retrofit techniques for exterior beamcolumn joints should be designed and constructed considering the architectural requirements of the existing buildings, and thus a minimum retrofit is usually allowed by building owners. In the studies by Bakis et al. (2002) and Del Vecchio et al. (2014), it was indicated that the seismic performance of the beam-column joints could be effectively enhanced even by strengthening one side of the joint panel zones.

In this study, for minimum and efficient retrofit of exterior beam-column joints, various practical rehabilitation solutions were proposed using internally embedded head re-bars, carbon fiber reinforced polymer (CFRP) wrapping, steel haunch elements, and steel jacketing. Thus, to verify the proposed retrofit methods, experimental studies were performed. In total, seven half-scale test specimens were constructed; one was a control specimen and the other six specimens were retrofitted with different proposed retrofit methods. All test specimens were then tested under simulated seismic loading. The structural performance of retrofitted exterior beam-column joints was analysed in terms of various factors: load-drift hysteretic behavior, stiffness, dissipated energy, and damping ratio. The purpose of this experimental program was aimed at providing better understanding of seismic performance of the concrete beam-column joints strengthened with different retrofit materials. An advancement of practical retrofit solutions for the beam-column joints could be adopted based on the findings in the current studies.

\section{Experimental Program}

\subsection{Test Specimens}

From the study by Priestley (1997), it was found that in the existing buildings, which were designed to resist mainly gravity loads, beam-column joints could not perform well 
under seismic loading. This was mainly due to the fact that poor confinement details led to low ductility of the beamcolumn joints.

In Korea, based on the report investigated by the Korea National Emergency Management Agency (2011), the beam-column joints of buildings constructed during the 1980s did not satisfy the requirement of seismic reinforcement details in current design codes. In such existing buildings, stirrups or ties with $90^{\circ}$ hooks and large spacing were used, and the anchorage of the top longitudinal reinforcing bars of beams was bent down inside the connection regions, while the anchorage of the bottom longitudinal reinforcing bars was bent down away from the connection regions, which might decrease the strength and deformation capacity of the connections (Priestley 1997; the Korea National Emergency Management Agency 2011).

In this study, to investigate the seismic performance of reinforced concrete frames after retrofitting, seven exterior non-retrofitted concrete beam-column joint specimens with a scale factor of $1 / 2$ were designed, detailed, and constructed in accordance with the Korea building code (AIK 1982). The purpose was to simulate the exterior beam-column joints of existing RC frame buildings constructed in 1980s in Korea. One of these specimens was used as a control specimen and the other six specimens were retrofitted by various retrofit methods. Figures 2, 3, 4, 5, 6, 7, 8 and Table 1 present the geometries and details of all test specimens. The control specimen was denoted as $\mathrm{J}-0$, as shown in Fig. 2 . In the figure, a beam with a cross section of $200 \mathrm{~mm} \times 300 \mathrm{~mm}$ was connected to a column with a cross section of $300 \mathrm{~mm} \times 300 \mathrm{~mm}$ at the mid-height point. The squareshaped cross section of the columns was determined after Antonopoulos and Triantafillou (2003) and Shafaei et al. (2014). It is noted that the purpose of this study was to investigate the seismic performance beam-column joints failed in $\mathrm{J}$ failure mode, and thus the joint shear strength of a control specimen $\mathrm{J}-0$ was determined to be less than the joint shear demand corresponding to flexural yielding of the beams (Lee et al. 2009). In addition, to avoid column failure ahead of joint failure, the longitudinal reinforcement ratio of the column was determined as $3.4 \%$, and the top and bottom longitudinal reinforcement ratios of the beam were 3.5 and $0.43 \%$, respectively. The expectation of the failure modes of the beam-column joints is presented in Appendix 1. It is noted that J-0 has the same material and geometrical properties as those of the retrofitted specimens, except for the retrofitted parts.

The aim of retrofitting the exterior joints was to enhance the ductile behavior after failure of the joints by providing half joint shear strength $\left(0.5 V_{c}\right)$ as residual strength by shear reinforcement (see Appendix 2). For practical purposes, high seismic performance of the joints was not considered an aim of the study. In addition, it should be noted that in test specimens, only a portion of the joint panel zones was retrofitted with retrofit materials to minimize the retrofit of transverse beams and floor slabs in real structures. Figure 3 shows the details of specimen J-A, which was strengthened with head re-bars having a diameter of $16 \mathrm{~mm}$, a length of

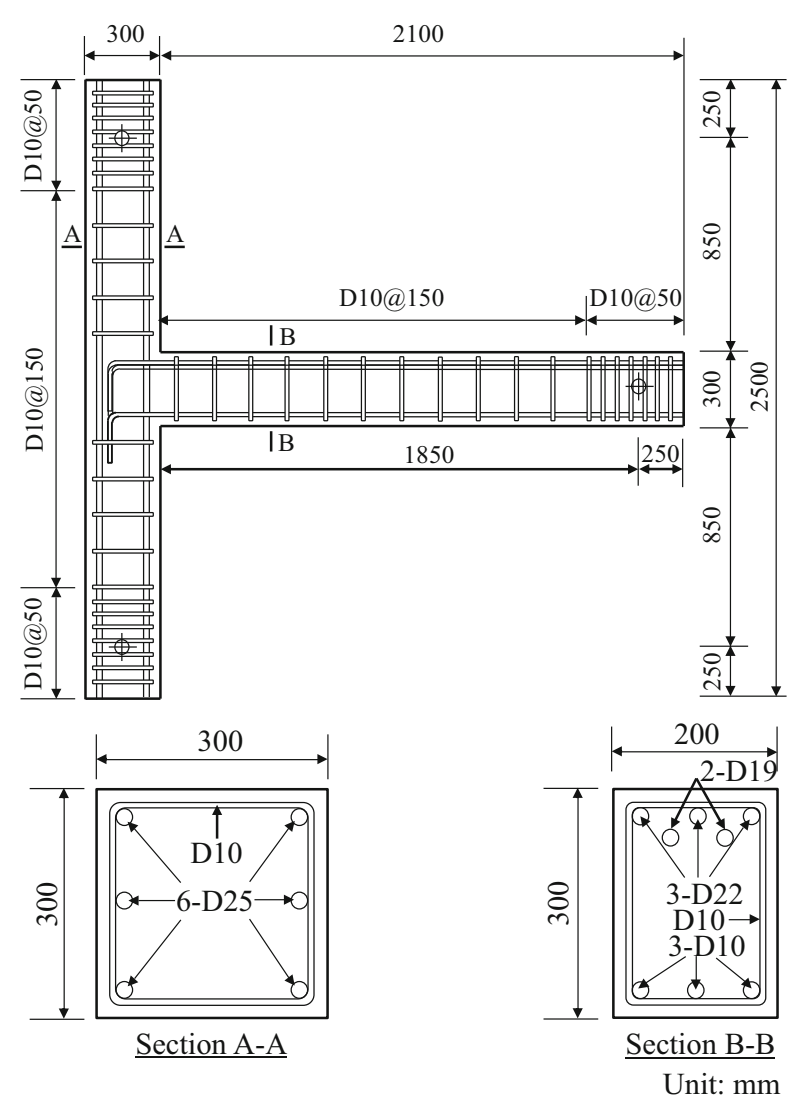

Fig. 2 Details of control specimen J-0.

$300 \mathrm{~mm}$, and specified yield strength of $400 \mathrm{MPa}$. In the figure, eight head re-bars were equally installed into two vertical lines with $150 \mathrm{~mm}$ spacing in the joint panel zone. For each vertical line, four head re-bars were installed with a vertical spacing of $50 \mathrm{~mm}$ to each other (ACI 318-14 2014).

The details of specimen J-CFRP are presented in Fig. 4. J-CFRP was wrapped with two plies of CFRPs and then fixed with a vertical line of ten CFRP anchors along the column. The CFRPs used have a length of $1100 \mathrm{~mm}$ and a width of $100 \mathrm{~mm}$, and only two sides of the column section were strengthened with CFRPs. The presence of CFRPs was expected to improve the joint confinement and to avoid the failure of the CFRP anchors (Ozbakkaloglu and Saatcioglu 2009; Brena and McGuirk 2013). It is noted that in this study only one specimen strengthened with CFRPs was tested. In fact, many other strengthening layouts of FRPs, in particular, at the corners between columns and beams were investigated and showed good retrofit effect (Del Vecchio et al. 2014; Mahmoud et al. 2014).

Figure 5 shows the details of specimen $\mathrm{J}-\mathrm{H}$, which was strengthened with haunch elements made by steel plates (SS400) having a thickness of $16 \mathrm{~mm}$ and specified yield strength of $400 \mathrm{MPa}$. In the figure, the plastic hinge regions of the beam and column below the beam, which were adjacent to the joint panel zone, were three-sided (or U-shaped), strengthened with steel gutters, and connected together by a diagonal steel plate to form a haunch. In addition, two sides of the steel gutters were installed with 


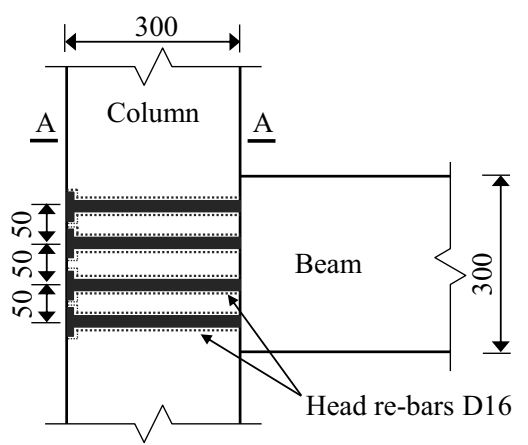

(a) Elevation

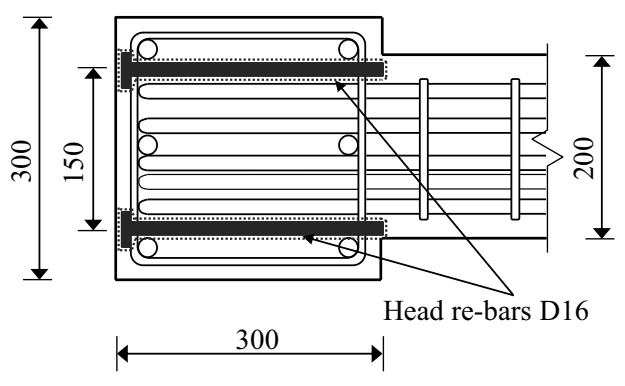

(b) Section A-A

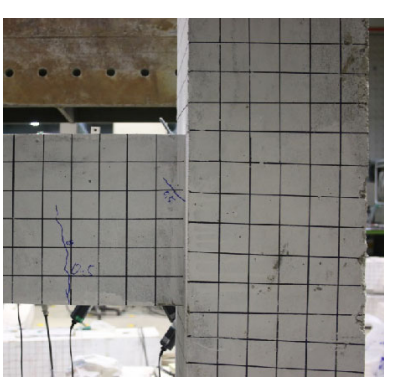

(c) Photo of J-A

Unit: $\mathrm{mm}$

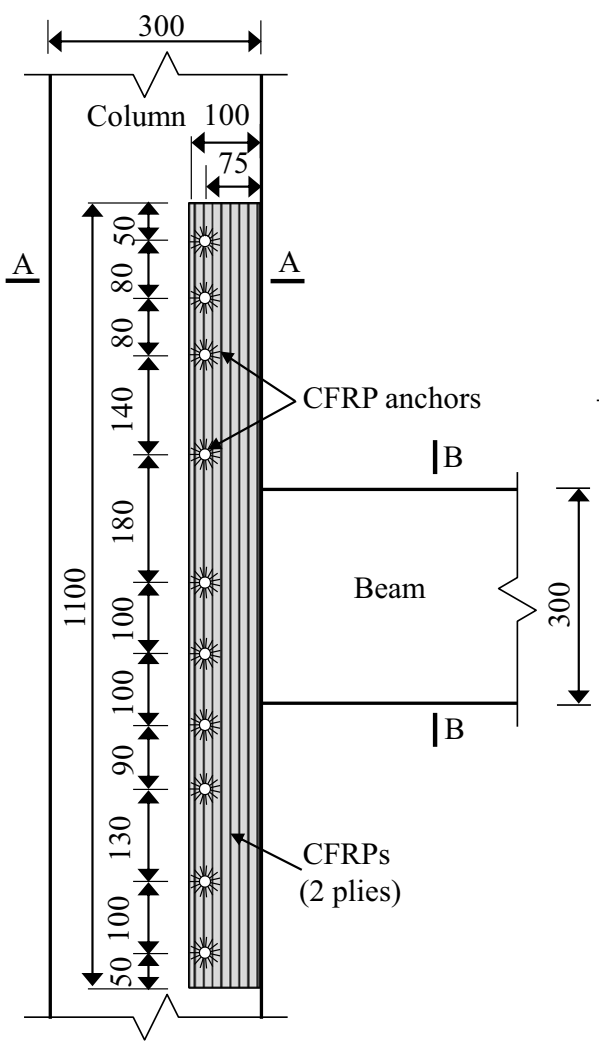

(a) Elevation

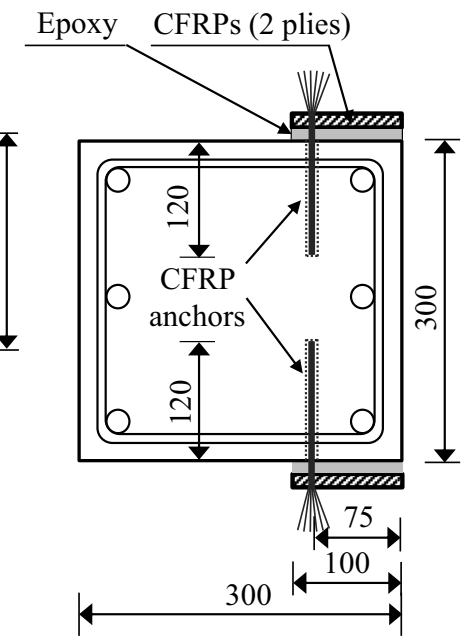

(b) Section A-A

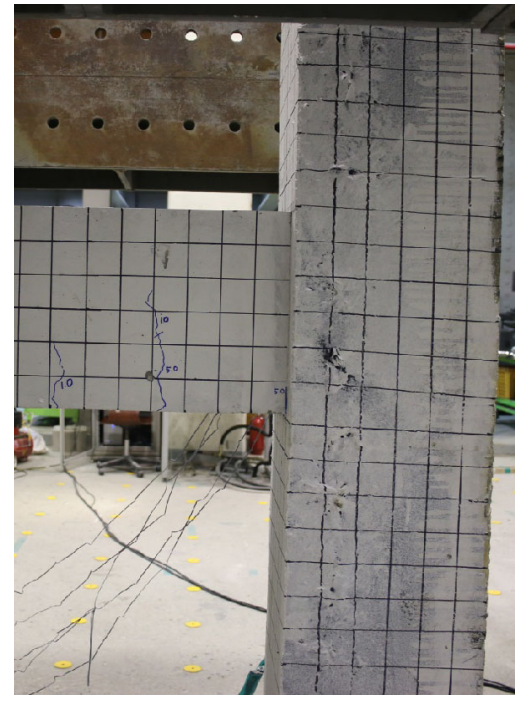

(c) Photo of J-CFRP

Unit: $\mathrm{mm}$

Fig. 4 Details of retrofitted specimen J-CFRP.

anchor bolts HILTI HSL-3 M12/20 (the diameter of $12 \mathrm{~mm}$ and the length of $120 \mathrm{~mm}$ ). It is noted that haunches are expected to change the failure mode from $\mathrm{J}$ failure to $\mathrm{BJ}$ or $\mathrm{B}$ failure. The evaluation of the strength of the steel haunch elements is presented in Appendix 3. In this study, the $\beta$ (and $\beta^{\prime}$ ) factor (which was used to determine the redistribution of the shear between the beam, column, and haunch elements in the joint) is equal to 2.69 , indicating that the bending moments and the shear forces in the beams and columns could be reduced by up to $30 \%$. Haunches were not installed in the upper story of the joint to avoid architectural inconvenience after the retrofit because the haunches could occupy the space in the upper story.
Figures 6,7 , and 8 show the details of specimens J-SJ1, $\mathrm{J}-\mathrm{SJ} 2$, and J-SJ3, respectively, which were strengthened with steel jackets (SS400) having a thickness of $16 \mathrm{~mm}$ and the specified yield strength of $400 \mathrm{MPa}$. The difference between the three specimens was the steel jacketing configuration. In specimen J-SJ1 (Fig. 6), the two opposite sides of the column have straight steel plates with a width of $100 \mathrm{~mm}$ and a length of $1100 \mathrm{~mm}$. In specimen J-SJ2 (Fig. 7), two opposite sides of the column are strengthened with U-shaped steel plates having a width of $100 \mathrm{~mm}$, a height of 200, and a length of $1100 \mathrm{~mm}$. Specimen J-SJ3 (Fig. 8) was strengthened with two steel plates placed along the columns with a length of $510 \mathrm{~mm}$. In addition, two other steel plates with a 
(c) Section B-B

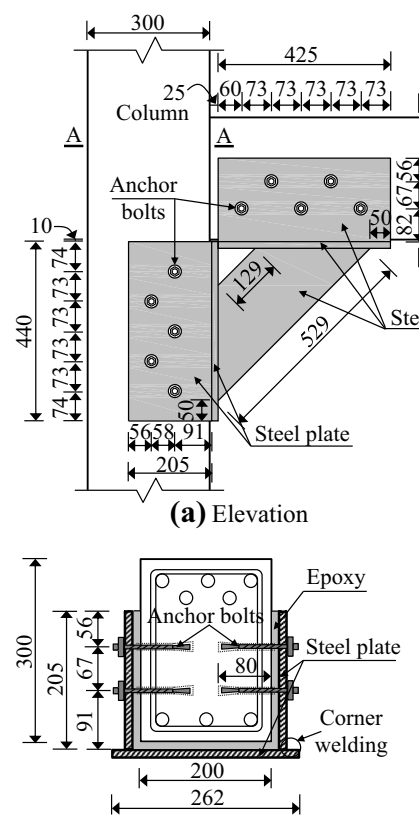



(b) Section A-A

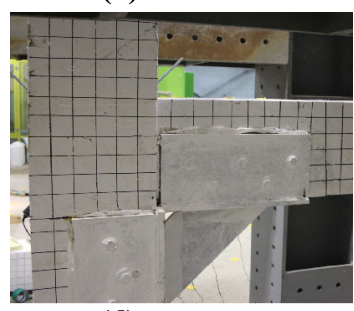

(d) Photo of J-H Unit: $\mathrm{mm}$

Fig. 5 Details of retrofitted specimen $\mathrm{J}-\mathrm{H}$.

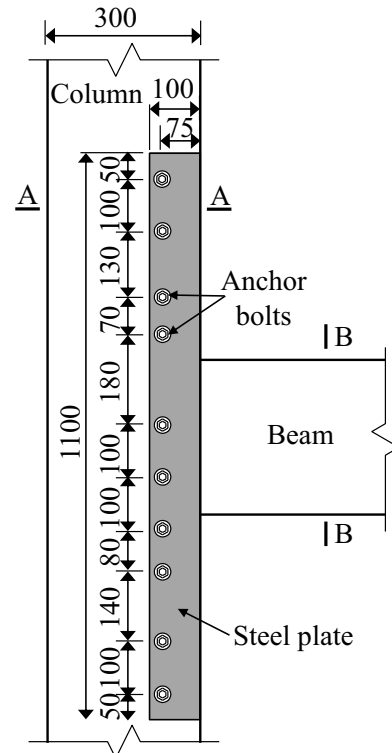

(a) Section A-A

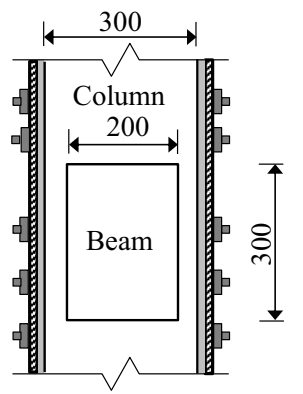

(c) Section B-B

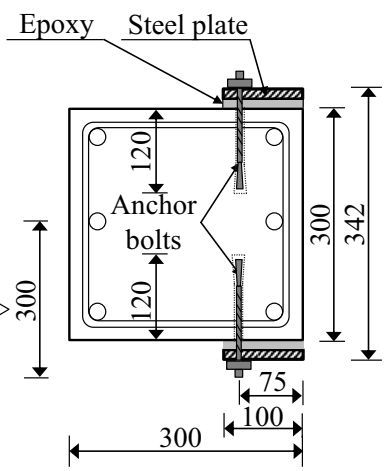

(b) Section A-A

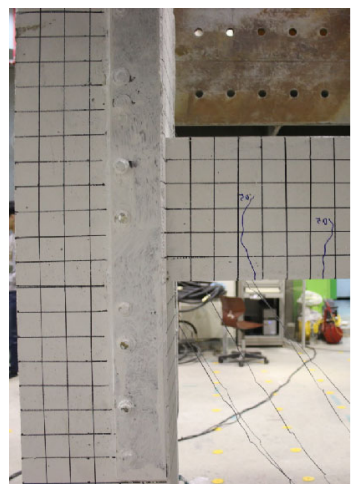

(d) Photo of J-SJ1

Unit: $\mathrm{mm}$
Fig. 6 Details of retrofitted specimen J-SJ1.

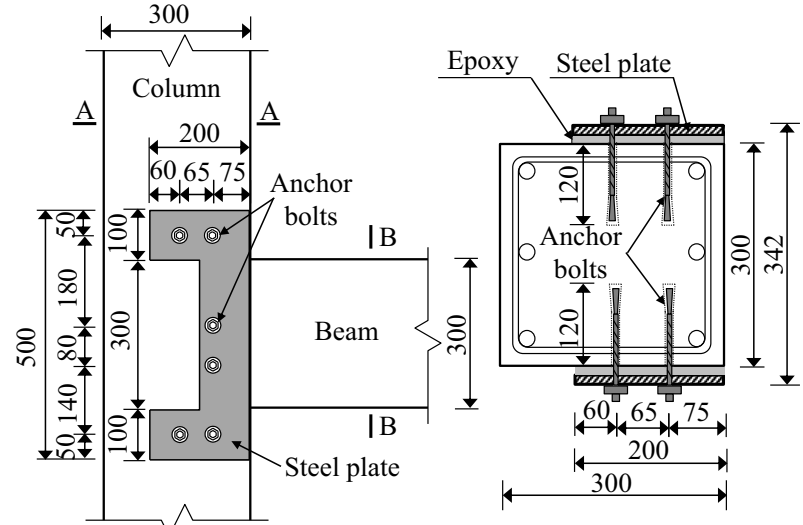

(a) Elevation



(c) Section B-B (b) Section A-A

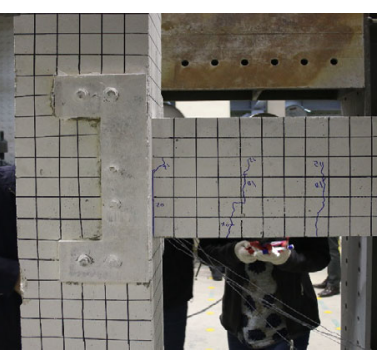

(d) Photo of J-SJ2
Fig. 7 Details of retrofitted specimen J-SJ2.

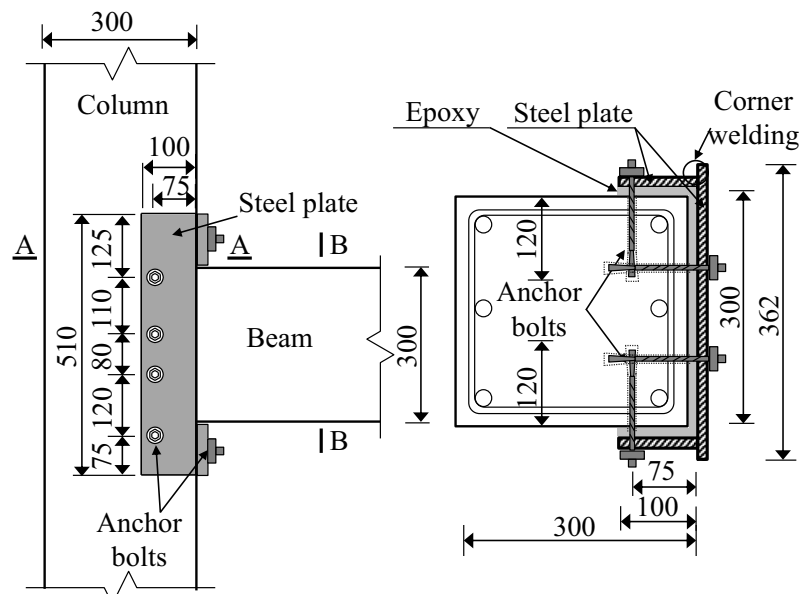

$\begin{array}{ll}\text { (a) Elevation } & \text { (b) Section A-A }\end{array}$

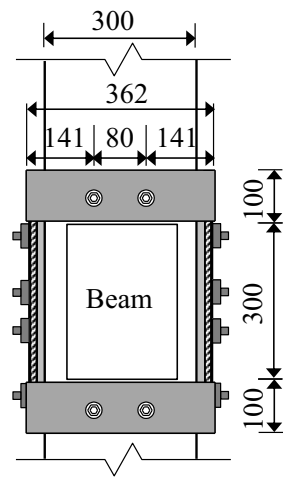

(c) Section B-B

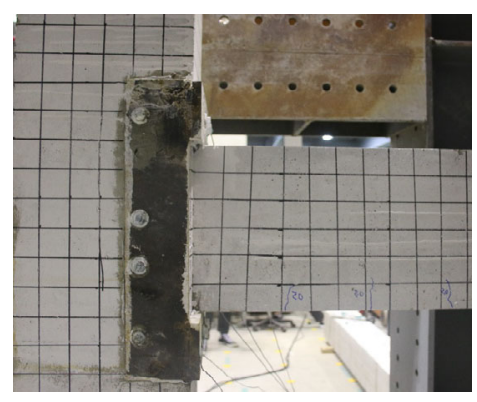

(d) Photo of J-SJ3 Unit: $\mathrm{mm}$

Fig. 8 Details of retrofitted specimen J-SJ3 


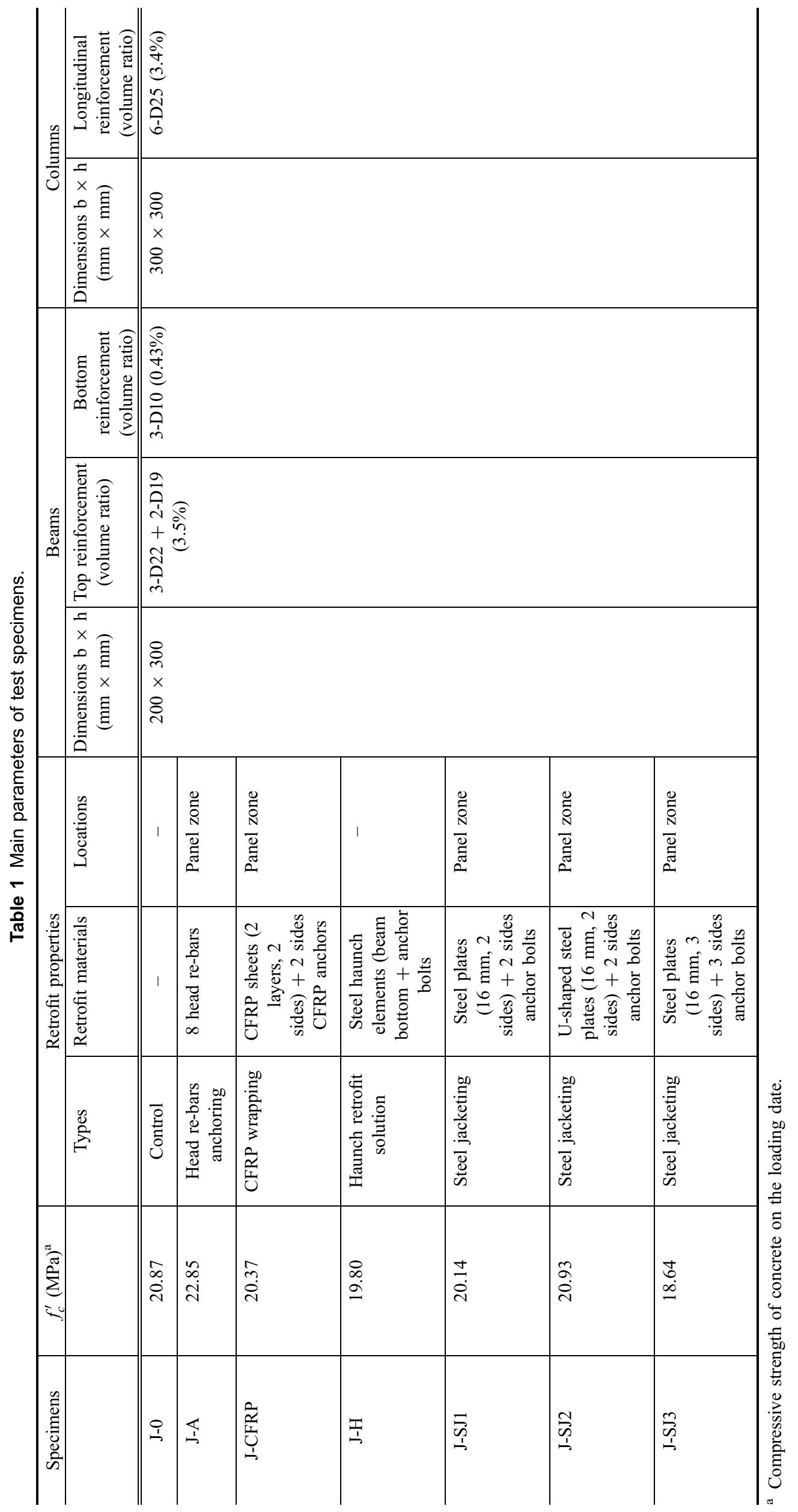


length of $362 \mathrm{~mm}$ and a width of $100 \mathrm{~mm}$ were also placed on the column faces above and below the beam. In all three specimens, the steel jackets were also installed with anchor bolts (HILTI HSL-3 M12/20). The area of the steel plates was designed to avoid the failure of the anchor bolts (ACI 318-14 2014). The evaluation of the shear strength contributed by retrofit materials is presented in Appendix 4.

\subsection{Materials}

To investigate the seismic performance of the existing concrete frame buildings constructed during the 1980s in Korea (AIK 1982), a low compressive strength of concrete $\left(f_{c}^{\prime} \approx 18 \mathrm{MPa}\right)$ and yield strength $\left(f_{y} \approx 300 \mathrm{MPa}\right)$ of steel re-bars were used. Table 1 shows the average compressive strength of each specimen at the loading day, which was determined based on the compressive tests according to KS F 2405 (2010). In the table, the compressive strengths for all specimens ranged from 18.64 to $22.85 \mathrm{MPa}$.

A tension test of the steel reinforcing bars was also performed following the guidance specified in KS B 0802 (2013) and 0814 (2001). The specified yield strength of the D10, D19, D22, and D25 steel reinforcing bars is $300 \mathrm{MPa}$. The average yield strengths obtained, $f_{y}$, of steel re-bars were 406, 375, 383, and $392 \mathrm{MPa}$ for the D10, D19, D22, and D25, respectively, exceeding the specified yield strength of $300 \mathrm{MPa}$. Figure 9a shows the typical stress-strain relationship of steel re-bars for D19 acquired from the test.

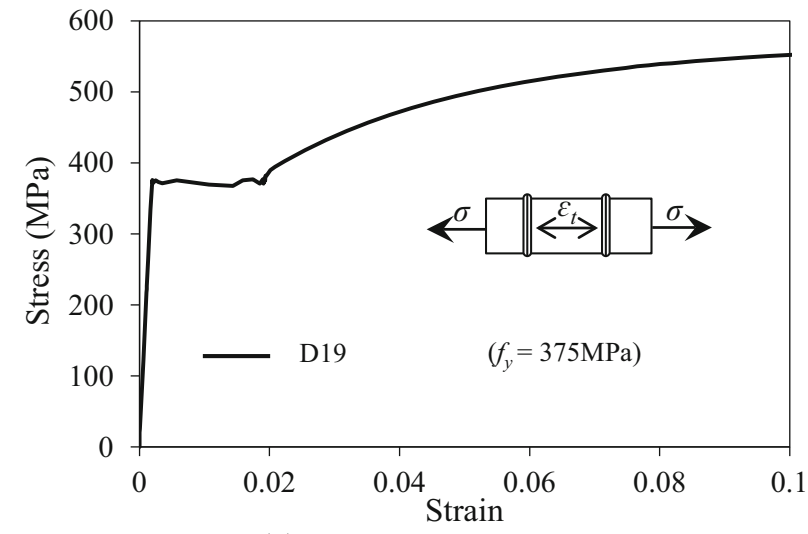

(a) Tensile test of steel re-bars

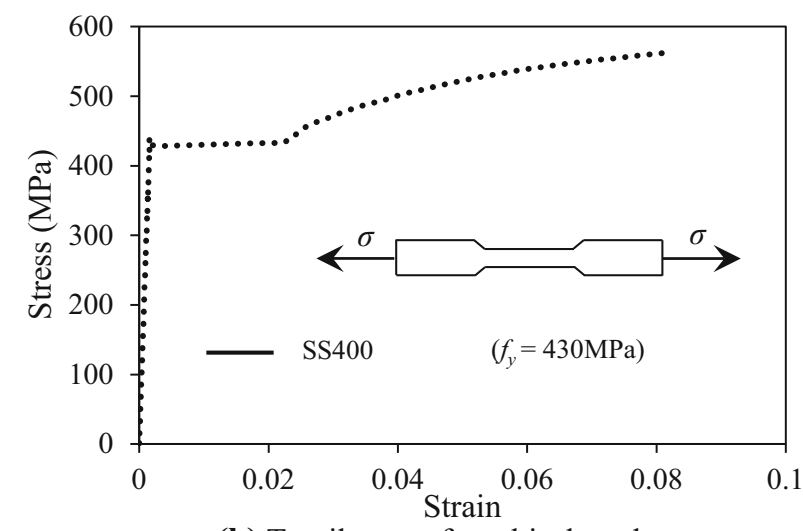

(b) Tensile test of steel jacket plates

Fig. 9 Testing of materials: a tensile test of steel re-bars and b tensile test of steel jacket plates.
The CFRPs used had the average thickness of $0.293 \mathrm{~mm}$, the ultimate strain of 0.015 , the ultimate tensile strength of $3450 \mathrm{MPa}$, and the elastic modulus of $230,000 \mathrm{MPa}$ as values provided by the manufacturers. The head anchor bolts used in specimen $\mathrm{J}$-A has a diameter of $16 \mathrm{~mm}$ and the specified tensile strength of $400 \mathrm{MPa}$. Figure $9 \mathrm{~b}$ presents the tensile test of the steel jacket plates (SS400) used in this test. In the figure, the yield strength of SS400 was $430 \mathrm{MPa}$, exceeding the specified yield strength of $400 \mathrm{MPa}$. Hereafter, in the evaluation of the experimental results in this study, the material strength obtained from the tests is used instead of the specified strength of concrete, steel re-bars, and retrofit materials.

\subsection{Test Setup}

A strong three-dimensional steel frame was assembled to carry out testing of the beam-column connections subjected to cyclic lateral loading. Figure 10 presents a schematic drawing and photos of the test setup. In the figure, the column of the connection was placed in a vertical position and the beam was placed in a horizontal position. The test specimens were considered to be hinged at both column ends: the top and the bottom ends of the columns were connected to a hydraulic actuator and strong floor, respectively. In addition, lateral cyclic loading was applied to the top part of the columns, simulating earthquake loading by a $500 \mathrm{kN}$ hydraulic actuator. The end of the beam was pinned by an axial steel link pin connected at its base. A lateral
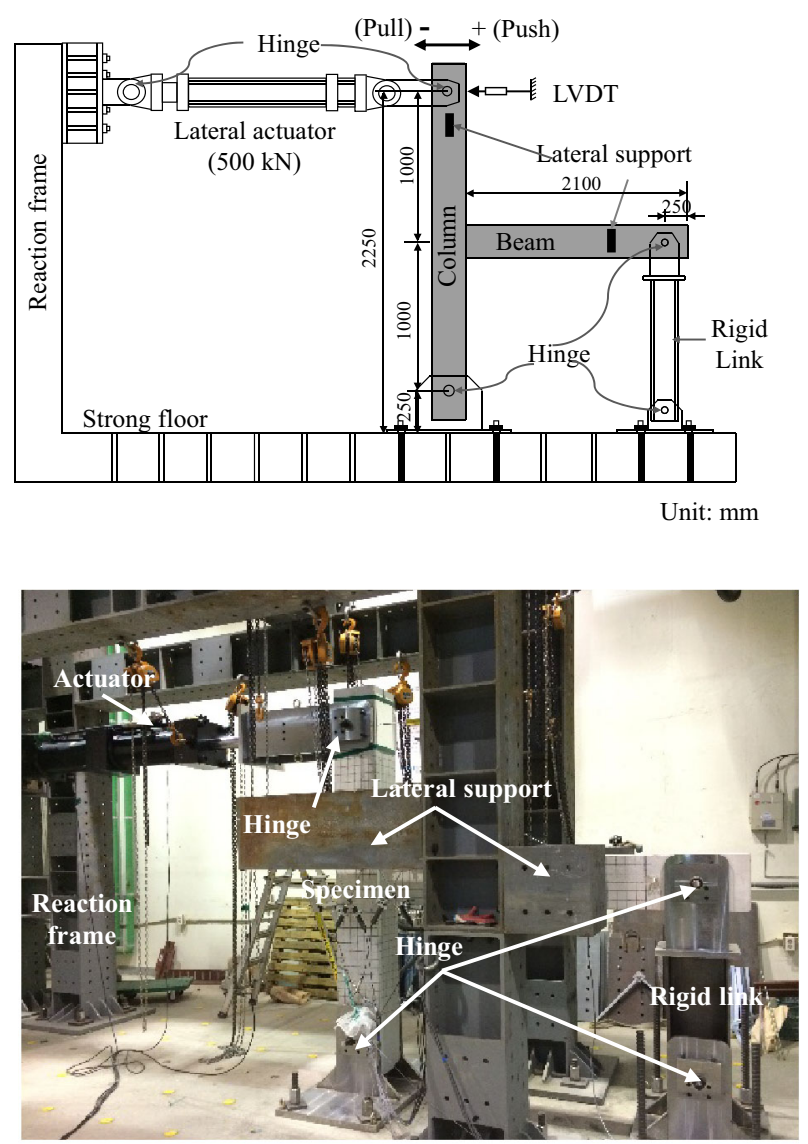

Fig. 10 Test setup. 
support system was connected to a reaction frame to prevent out-of-plane movement of the test specimens.

Figure 11a presents the cyclic loading history used in this test according to the guide of ACI 374.2R-13 (2013). In the figure, two cycles were repeated at each drift ratio level of $0.25,0.5,0.75,1,2,3,4,5 \%$, and so on until failure. The determination of the drift ratio is shown in Fig. 11b, which was mainly based on the ratio of the displacement and the length of the column. In this study, no axial load was applied on the top of the columns since such application of axial load increased the joint stiffness (Pantelides et al. 2002, 2008; Quintero-Febres and Wight 2001). However, further investigation is needed on the effect of the column compression force on the behavior of beam-column connections.

Figure 12 presents the location of the linear variable displacement transducers (LVDTs) attached to the control specimen. An LVDT TT1 was placed at the upper end of the column to measure the total lateral displacement. Shear deformation of the panel zones and the flexural and shear deformation of adjacent beams were measured by a set of LVDTs. It is noted that for retrofitted specimens, only LVDT TT1 was used to measure the lateral displacement. The other

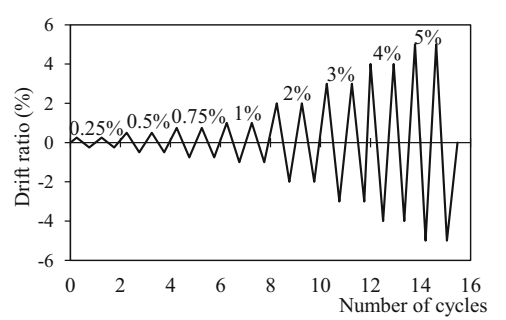

(a) Lateral displacement history

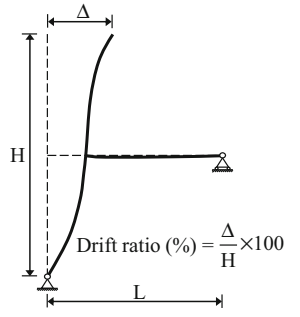

(b) Drift determination on column
Fig. 11 Loading protocol: a lateral displacement history and b drift determination on column.

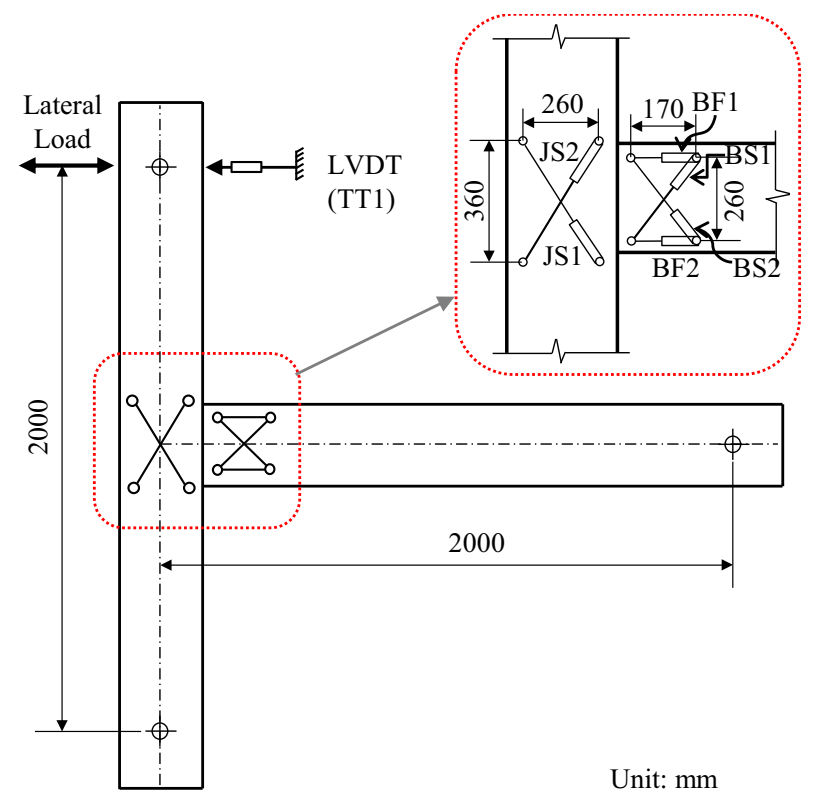

Note: Linear variable displacement transducer TT1 was used for all specimens

Fig. 12 Location of LVDTs in control specimen.
LVDTs were not attached to the retrofitted specimens due to the existence of the retrofit materials on the surfaces of the columns and beams around the joint panel zone.

Fourteen ordinary strain gauges were attached to the longitudinal and transverse reinforcing bars of the beams and columns around the joint panel zones to measure the steel strains developed during different loading stages. In addition, ordinary strain gauges were attached to the surface of the strengthening materials such as headed anchors, CFRPs, haunches, and steel jackets to measure the material strains. Figure 13 shows the arrangement of ordinary strain gauges. In the figure, the column reinforcing bars were gauged at the location directly above the connection part (strain gauges nos. 1 and 2). The beam reinforcing bars were gauged at two different locations: adjacent to the connection part (strain gauges no. 3-6) and inside the connections (strain gauges nos. 7-12) to check the yield penetration of beam reinforcement. Strain gauges nos. 13 and 14 were attached to measure the transverse re-bar strains of the columns and beams. Both the displacement and strain data were collected using the data acquisition system.

\subsection{Retrofit Techniques}

In this study, seven reinforced concrete beam-column connections were cast and six specimens were then retrofitted, excluding the control specimen. The retrofit process was carried out according to actual construction procedures. In the case of specimen J-A (Fig. 3), the holes were predrilled according to a designed configuration, and the work was carefully carried out to avoid damage of the internal concrete and steel re-bars. The head re-bars were then installed through the holes and completely filled with mortar. In the case of specimen J-CFRP (Fig. 4), before wrapping the CFRPs, the surfaces of the two column sides were carefully cleaned to coat an epoxy adhesive layer along the column length of $1100 \mathrm{~mm}$ to ensure the bonding between the CFRPs and the column surfaces. After this stage, two plies of CFRPs were wrapped on the prepared surfaces of the column. The CFRP anchors were then installed in the holes, which were pre-drilled and cleaned before coating with epoxy adhesive. It should be noted each CFRP anchor must be fully impregnated with epoxy adhesive to ensure the bond between the CFRP sheets and CFRP anchors (Grelle and Sneed 2013).

In order to strength specimen J-H (Fig. 5) with steel haunch elements, steel gutters were prefabricated from plateshaped steel plates and then assembled on the column and beam surfaces after coating with an epoxy adhesive layer. Anchor bolts were then installed through the pre-drilled holes at a length of $120 \mathrm{~mm}$ into the concrete column and beam. Finally, a steel plate was welded on site with the bottom surfaces of the steel gutters to form a haunch according to the designed configuration.

In specimens J-SJ1 (Fig. 6), J-SJ2 (Fig. 7), and J-SJ3 (Fig. 8), the steel jackets were prefabricated as plate-shaped (Figs. 6 and 8) and U-shaped panels (Fig. 7), and the steel jackets were then assembled on the column faces after coating with an epoxy adhesive layer. The anchor bolts were 


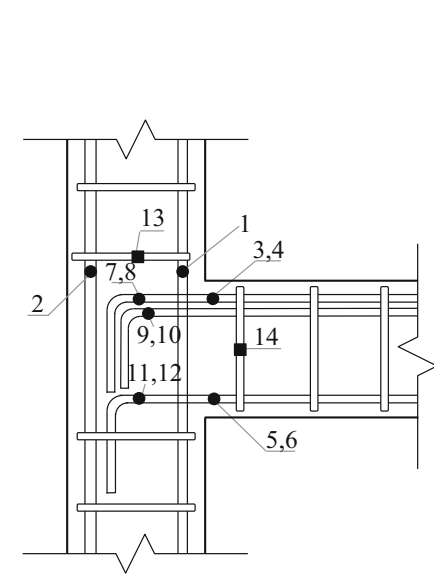

(a) Gauge arrangement

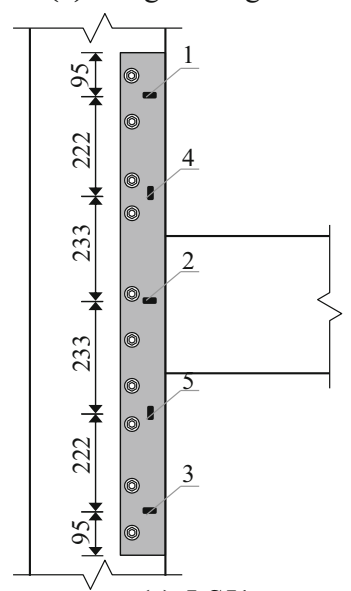

(e) J-SJ1

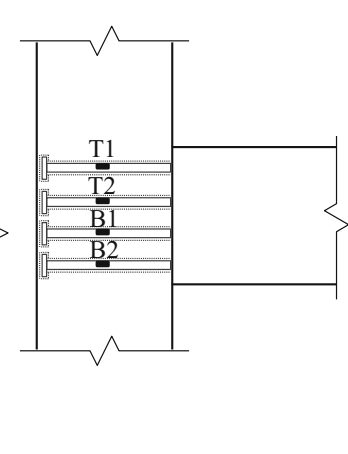

(b) J-A

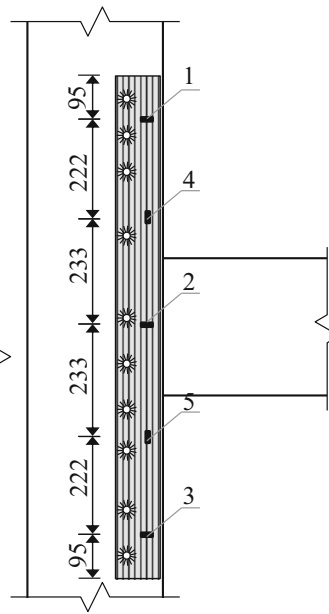

(c) J-CFRP

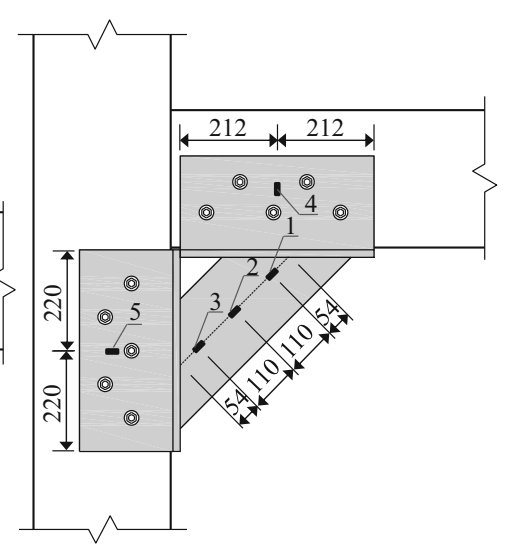

(d) $\mathrm{J}-\mathrm{H}$

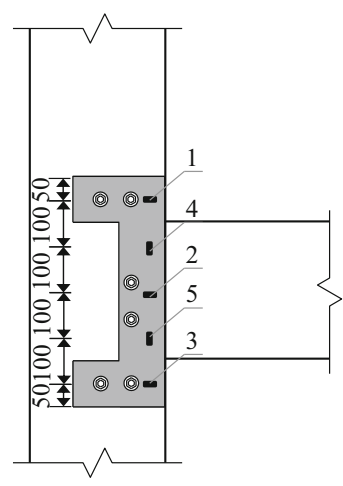

(f) $\mathrm{J}-\mathrm{SJ} 2$
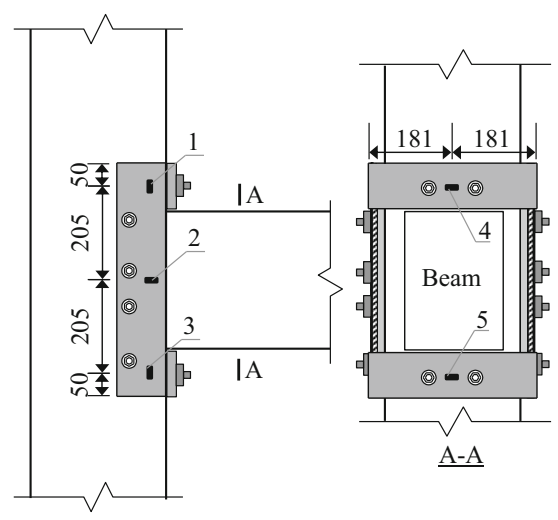

(g) $\mathrm{J}-\mathrm{SJ} 3$

- Ordinary strain gauges (longitudinal steel re-bars in columns and beams)

- Ordinary strain gauges (transverse steel re-bars in columns and beams)

- Ordinary strain gauges at the retrofit location to measure strain of steel jackets, CFRPs, head steel re-bars

Unit: mm

Fig. 13 Arrangement of strain gauges attached to steel re-bars and retrofit surfaces: a gauge arrangement, b J-A, c J-CFRP, d J$\mathrm{H}$, e J-SJ1, f J-SJ2, and g S-SJ3.

then installed through the pre-drilled holes at a length of $120 \mathrm{~mm}$ into the concrete columns. Finally, in specimen J-SJ3, the free ends of the steel jackets were welded together.

\section{Experimental Results and Discussion}

\subsection{Damage Observations}

Figure 14 shows the damage observation and crack pattern at the end of testing. In the case of control specimen J-0 (Fig. 14a), flexural cracks initially appeared at a drift level of $0.5 \%$ from the bottom of the beam and quickly propagated to the neutral axis of the beam at a drift level of $1.0 \%$. Then, at a drift level of $1.5 \%$, thin flexural cracks appeared at the beam-column interface and spread along the beam length. With repeating loading cycles, inclined cracks first began to occur in the joint panel zone at a drift level of $3.0 \%$ for the negative direction of loading (in Fig. 15, the negative axis of drift ratio corresponds to the case where the beam is subjected to negative bending moment). Then, numerous inclined cracks in the joint panel zone with a large width increased as the loading progressed, indicating shear failure of the joint panel zone. After the occurrence of the inclined cracks in the joints, the width of the cracks continued to increase and the cracks in the beams ceased to increase. Subsequently, at a drift level of 5\%, several thin vertical and horizontal cracks appeared in the joint panel zone; in addition, flexural cracks appeared at the widened beam-column interface, which was attributed to the slippage of the bottom reinforcing bars of the beam. The test was intentionally terminated at a drift level of $12 \%$, and no significant crushing of concrete was observed at the end of testing in the plastic hinge regions of the beam and column; in particular, no spalling of concrete cover occurred in the joint panel zone, regardless of the presence of major inclined cracks with the large width.

The overall behavior of specimens J-A (Fig. 14b), J-CFRP (Fig. 14c), J-SJ1 (Fig. 14e), J-SJ2 (Fig. 14f), and J-SJ3 (Fig. 14g), which were strengthened with head re-bars, CFRPs, and steel jackets, respectively, was similar to that of control specimen J-0. However, in the cases of J-A, J-SJ1, $\mathrm{J}-\mathrm{SJ} 2$, and J-SJ3, the number of cracks in the joint panel zones was significantly reduced; in addition, the joint inclined crack width in J-A was narrower than that of control specimen J-0. This was because the use of head re-bars and steel jackets were effective in arresting the crack 


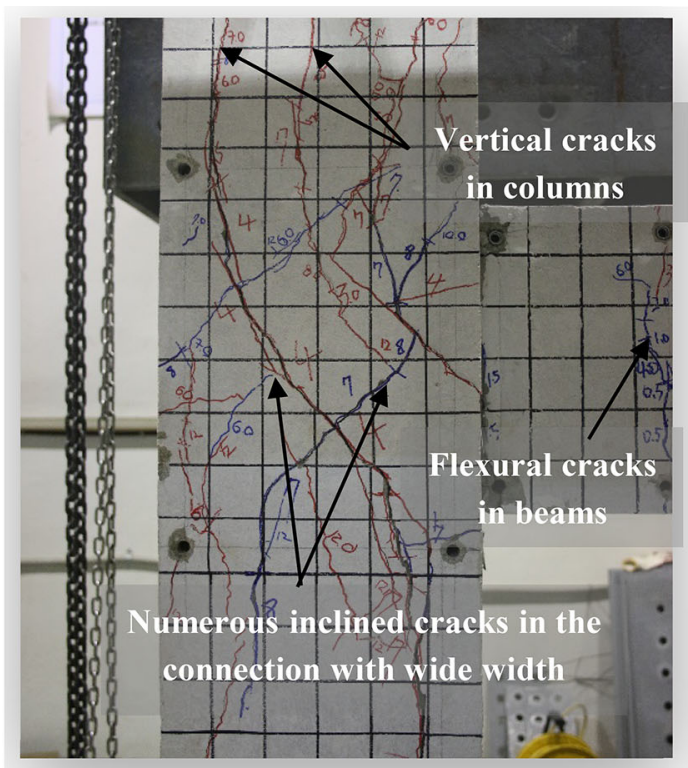

(a) J-0

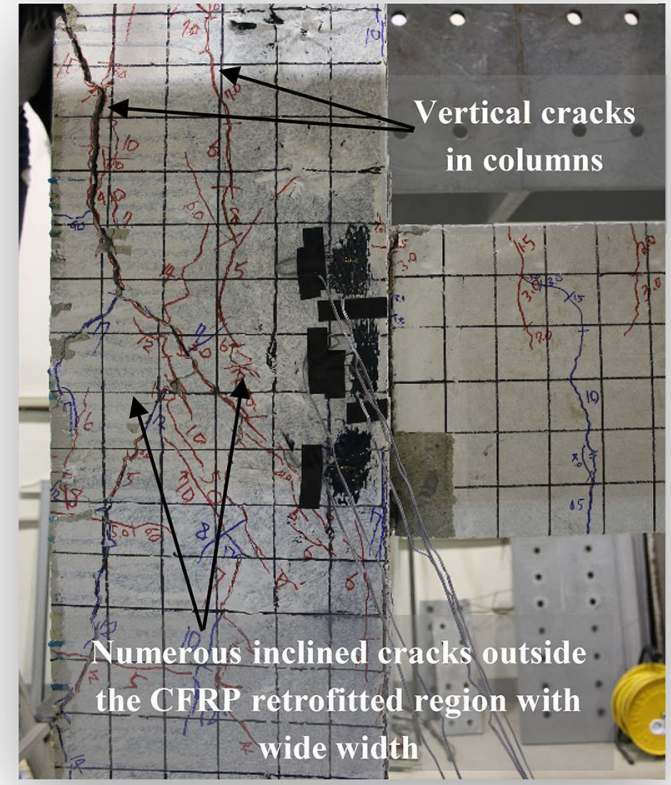

(c) J-CFRP

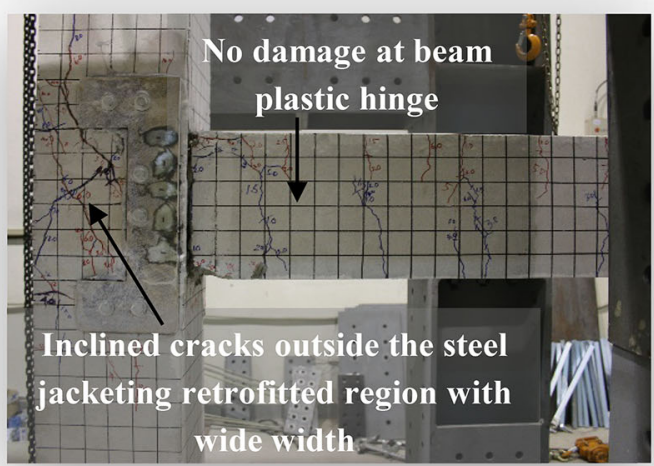

(f) $\mathrm{J}-\mathrm{SJ} 2$

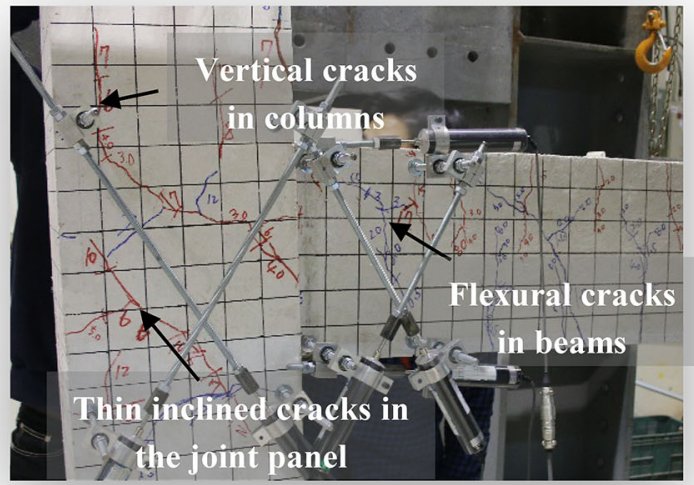

(b) J-A

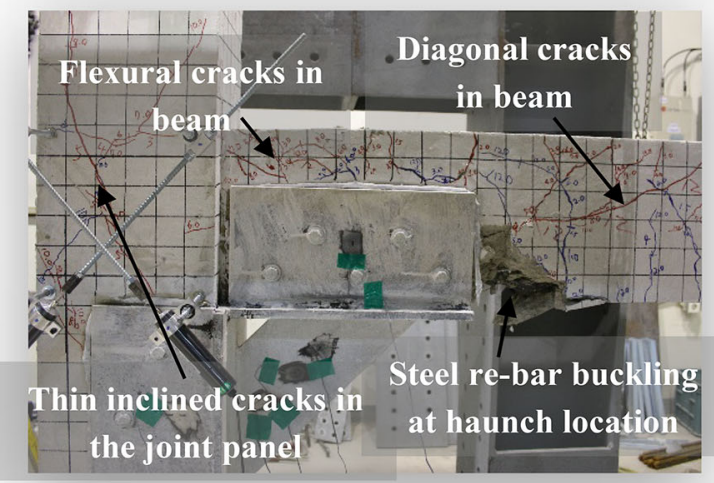

(d) $\mathrm{J}-\mathrm{H}$

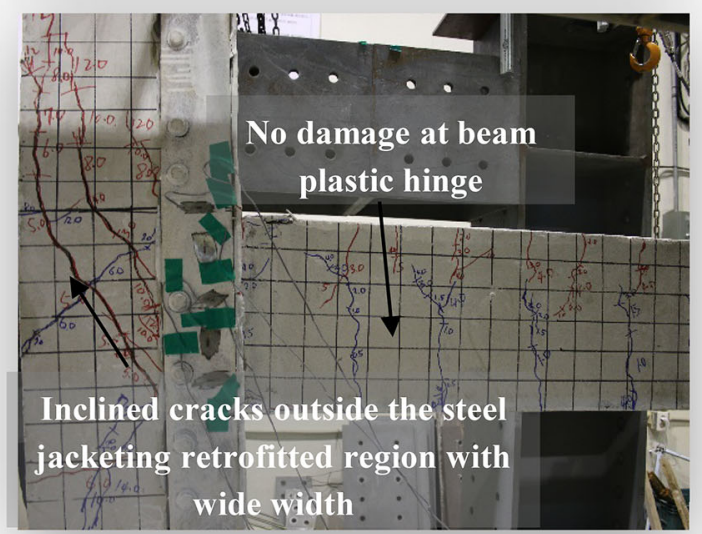

(e) J-SJ1

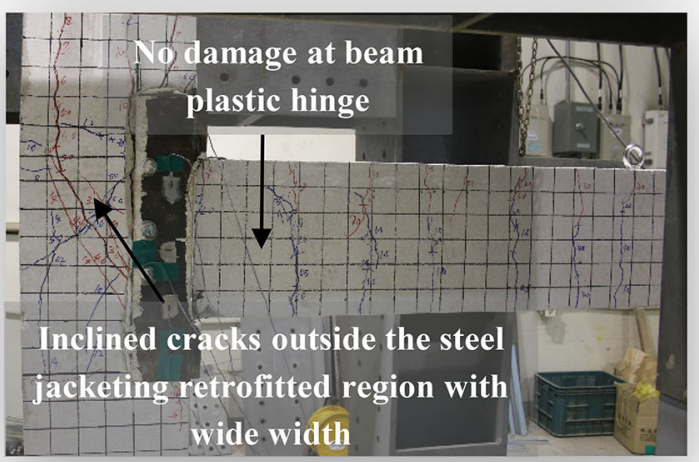

(g) $\mathrm{J}-\mathrm{SJ} 3$

Fig. 14 Specimen damage at the end of testing: a J-0, b J-A, c J-CFRP, d J-H, e J-SJ1, f J-SJ2, and g J-SJ3.

development. Moreover, in the case of J-SJ3, by using the proposed retrofit method, the slippage of the beam bottom reinforcing bars was significantly prevented. At the end of testing (at a drift level of 12\%), no spalling of concrete cover was observed in the joint panel zones. The failure of these retrofitted specimens, except for J-SJ3, was characterized by the beam failure in the negative direction of loading with wide flexural cracks at the beam-column interfaces. 

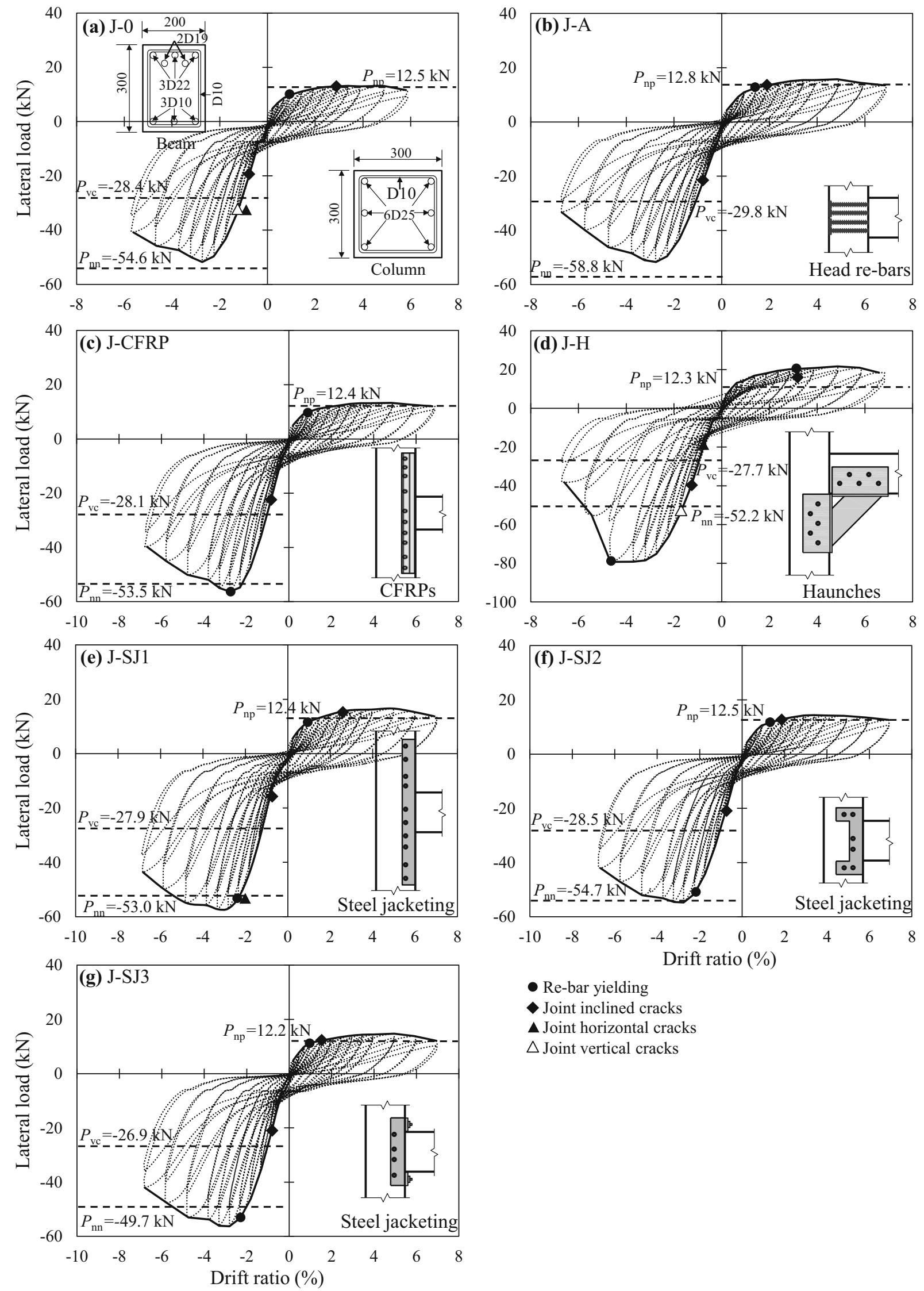

- Re-bar yielding

- Joint inclined cracks

A Joint horizontal cracks

$\triangle$ Joint vertical cracks

Fig. 15 Load-drift hysteretic relationships of test specimens.

Figure 14d shows the damage and crack pattern of specimen $\mathrm{J}-\mathrm{H}$, which was strengthened with haunch elements. First, at a drift level of $1.0 \%$, flexural cracks appeared in the beam; with the increasing drift level, numerous flexural cracks newly developed but the crack width was significantly narrower than that of J-0. From the 
drift level of $4 \%$, several thin inclined cracks appeared in the joint panel zone and in the beam for a negative direction of loading. With repeating loading cycles, at a drift level of $10 \%$, concrete crushing was observed in the beam outside the retrofitted part accompanying the buckling of the beam bottom longitudinal re-bars. This was attributed to the effects of stress concentration caused by the haunch element, leading to a brittle local failure in the beam and a sudden loss of load-carrying capacity (Sharma et al. 2010; Genesio 2012). In addition, the obtained test results indicated that the use of haunch elements resulted in the relocation of the plastic hinge region from the interface between the column and the beam to the beam.

\subsection{Load-Drift Hysteretic Relationships}

Figure 15 shows the load-drift hysteretic relationships of the test specimens. In this study, drift ratio $(\theta)$ was defined as $\Delta / H$, where $\Delta$ is the lateral displacement and $H$ is the column height (see Fig. 11b). The nominal lateral load-carrying capacities $\left(P_{n p}\right.$ and $\left.P_{n n}\right)$ of each specimen based on beam flexural strength were evaluated by using the actual material strength obtained from test results, where $P_{n p}$ and $P_{n n}$ are the positive and negative nominal lateral load-carrying capacities, respectively. In Fig. 15, $P_{n p}$ is less than $P_{n n}$ because the beams were designed to resist mainly gravity loads. $P_{v c}$ was also evaluated corresponding to joint shear strength.

In Fig. 15, in the negative direction of loading, the maximum lateral load was greater than that in the positive direction of loading because the top longitudinal reinforcement ratio of beams was greater than the bottom longitudinal reinforcement ratio. In the case of the control specimen J-0, the maximum lateral load was less than the values of $P_{n n}$ predicted based on beam flexural strength (Fig. 15a). This failure of the joint could be classified as shear failure.

In Fig. 15a, the control specimen J-0 exhibited high deformation capacity exceeding $5 \%$ in load-drift hysteretic response, even though pinching was severe and significant strength degradation was observed after the peak load. It is noted that the pinching effect of the load-drift hysteretic response leads to low energy dissipation of the specimens (Liang et al. 2016). In the negative loading direction, the yielding of longitudinal re-bars was not observed; meanwhile, in the positive loading direction, the longitudinal rebars had yielded at a drift ratio of $0.92 \%$. After yielding of the beam bottom longitudinal re-bars, the joint was damaged with numerous wide inclined cracks and several horizontal or vertical cracks.

The load-drift hysteresis loops of the retrofitted specimens were almost the same as that of the control specimen J-0. However, most retrofitted specimens except for J-A and J-SJ2 showed maximum lateral loads greater than the values predicted by beam flexural strength. This indicates that the joint failed after beam yielding. Thus, in the retrofitted specimens, the structural behavior would be relatively more ductile than that of J-0. In the J-SJ series, J-SJ1 and J-SJ3 were more effective than J-SJ2.

\subsection{Load-Drift Envelop Curves}

Figure 16 compares the load-drift envelop curves for all $\mathrm{RC}$ beam-column joints, which were strengthened with head re-bars, CFRPs, steel haunch elements, and steel jackets. In the envelop curves, the peak load, effective stiffness $\left(K_{e}\right)$, yield drift ratio $\left(\theta_{y}\right)$, ultimate drift ratio $\left(\theta_{u}\right)$, and drift ductility factor $(\mu)$ were determined. Figure 17 shows the definition of the deformation capacity and effective stiffness of a typical RC beam-column joint. In the figure, $K_{e}$ is the effective stiffness which is evaluated as an initial segment of the backbone curve; $\theta_{e}\left[=0.75 P_{\max } /\left(K_{e} L\right)\right]$ is the drift ratio corresponding to $0.75 P_{\max }$ in the ascending part of the envelop curve, where $L$ is the column length, $\theta_{y}$ is the yield drift ratio defined at $P_{\max }, \theta_{u}$ is the ultimate drift ratio at specimen failure (where a 20\% drop in the descending part of the envelop curve from the peak load is observed $\left.\left(0.8 P_{\max }\right)\right)$, and $\mu\left(=\theta_{u} / \theta_{y}\right)$ is the drift ductility factor at specimen failure and is determined by the ratio between the ultimate drift ratio at specimen failure and the yield drift ratio. Table 2 shows the effective stiffness $\left(K_{e}\right)$ and the deformation capacity $\left(\theta_{y}, \theta_{u}\right.$, and $\left.\mu\right)$ in the negative loading direction of all specimens.

In Fig. 16a, in the negative loading direction, the control specimen $\mathrm{J}-0$ reached the peak load of $-51.75 \mathrm{kN}$ at a drift ratio of $-2.75 \%$ and the ultimate drift ratio of $\mathrm{J}-0$ was $5.51 \%$. Meanwhile, in the case of specimen J-A, which was strengthened with the head re-bars, the peak load and deformation capacity of J-A were almost the same as those of J-0. In the case of specimen J-CFRP (Fig. 16b), with the wrapping of the CFRPs, the peak load and deformation capacity of specimen J-CFRP were slightly greater than those of J-0; however, the difference was not considerable. The peak load of J-CFRP was $-56.25 \mathrm{kN}$ at a drift ratio of $-2.78 \%$ and the ultimate drift ratio was $5.77 \%$. From the test results, CFRP wrapping is not effective in increasing either strength or deformability. However, it is noted again that only one specimen strengthened with CFRPs was tested and the strengthening layout of CFRPs used in this test was also newly developed. Meanwhile, in the studies by Realfonzo et al. (2014) and Singh et al. (2014), the beam-column joint specimens strengthened with various layouts of CFRPs were tested and the test results showed that the strength and ductility of beam-column joints could be increased up to approximately 72 and $98 \%$. Further research is necessary for better understanding this behaviour.

Specimen J-H, which was retrofitted with steel haunch elements, showed greater peak load than that of J-0 (Fig. 16c). In the negative direction of loading, J-H reached the peak load of $-79.31 \mathrm{kN}$ at a drift ratio of $-4.66 \%$, but the deformation capacity was not enhanced. It is clear that hunch elements are efficient in increasing the strength.

The peak load and deformation capacity of specimens $\mathrm{J}-\mathrm{SJ} 1$, J-SJ2, and J-SJ3, which were retrofitted with steel jackets, were slightly greater than those of J-0. In the negative loading direction, J-SJ1, J-SJ2, and J-SJ3 reached the peak loads of $-57.27,-54.71$, and $-56.31 \mathrm{kN}$ at the drift ratios of $-2.81,-2.75$, and $-2.81 \%$, respectively; the 


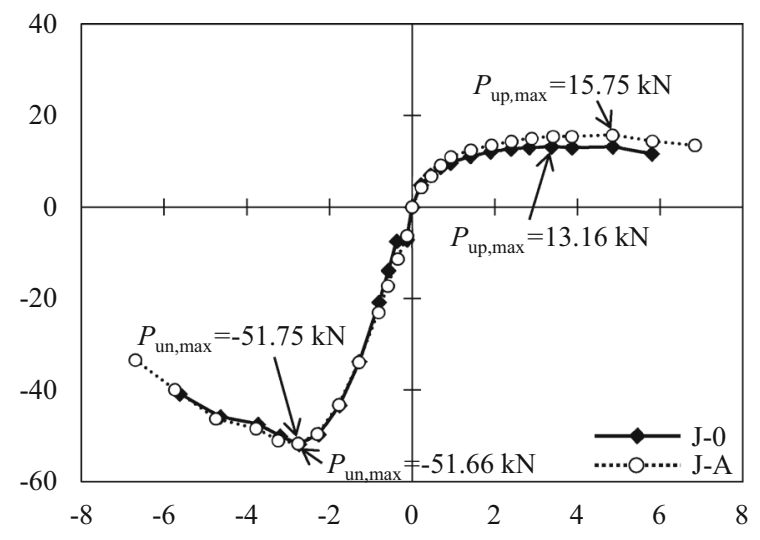

(a) Head re-bars

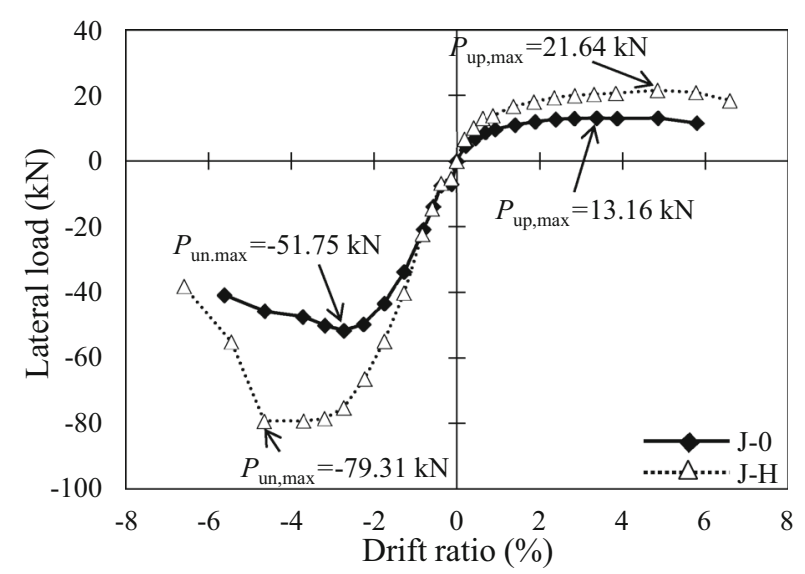

(c) Haunches

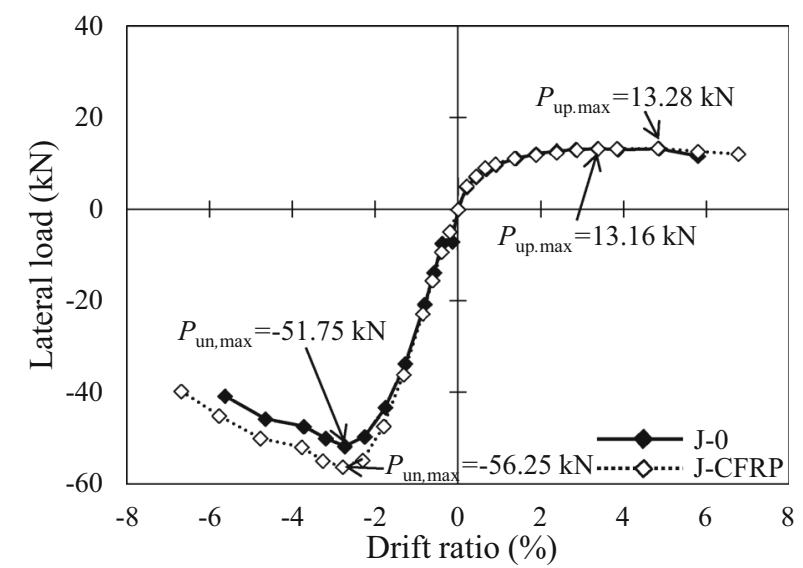

(b) CFRP wrapping

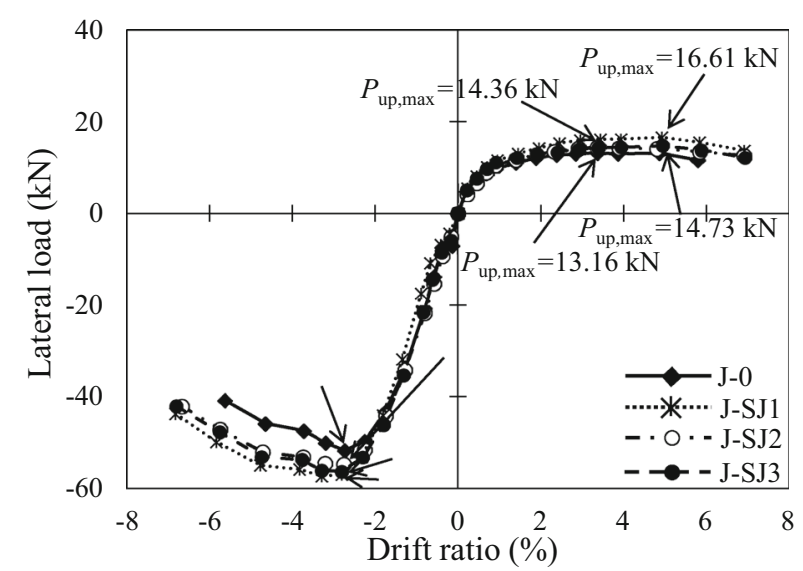

(d) Steel jacketing

Fig. 16 Effects of various retrofit applications on load-drift relationships: a head re-bars, b CFRP wrapping, $\mathbf{c}$ haunches, and d steel jacketing.

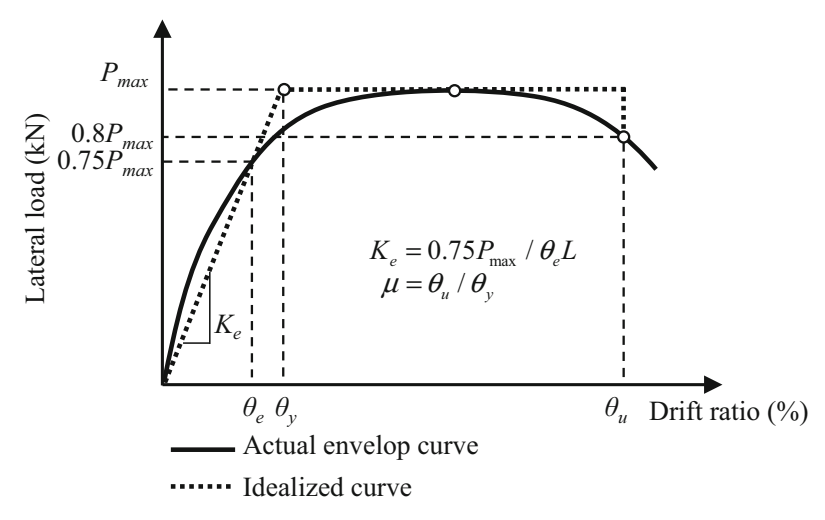

Fig. 17 Definition of drift ratios in idealized backbone curve.

ultimate drift ratios were $6.51,6.36$, and $6.26 \%$, respectively. From the test results, the J-SJ series using steel jackets are effective to increase both strength and deformability.

In addition, as shown in Table 2, the effective stiffness and yield drift ratio of $\mathrm{J}-\mathrm{H}$ were greater than those of $\mathrm{J}-0$ by approximately 20.47 and $27.45 \%$, respectively; meanwhile, the effective stiffness and yield drift ratio of the other retrofitted specimens were almost the same as those of J-0. Moreover, the drift ductility $(\mu)$ of the retrofitted specimens did not considerably differ from that of $\mathrm{J}-0$.

\subsection{Strain Profiles}

Figure 18 shows the strain profiles for longitudinal re-bars of the beams obtained from the test results. In Fig. 18a, the strains of the top longitudinal re-bars in the beams were the average values obtained from the steel strain gauges, namely 3 and 4, which were attached to the D22 re-bars and were located at the beam-column joint interface (see Fig. 13a). In the negative direction, as shown in Fig. 18a, the strains of the test specimens increased with the increasing drift ratio and did not show significant difference. The maximum strain of $\mathrm{J}-0$ and $\mathrm{J}-\mathrm{A}$ was -0.00147 at a drift ratio of $-2.74 \%$; thus, the longitudinal re-bar strains of J-0 and J-A did not reach their yield strain of -0.0015 ; this means that the beam top longitudinal reinforcement of $\mathrm{J}-0$ and $\mathrm{J}-\mathrm{A}$ remained in the elastic range. Meanwhile, the maximum strains of the retrofitted specimens ranged from -0.00151 to -0.00170 , exceeding their yield strain of -0.0015 . In the positive direction, yielding of the beam top longitudinal re-bars was not observed.

Figure $18 \mathrm{~b}$ shows the average strains of the beam bottom longitudinal re-bars, which were obtained from the steel strain gauges (namely 5 and 6) attached to the D10 steel rebars and located at the beam-column joint interface (see Fig. 13a). In the figure, in the positive direction, the longitudinal re-bar strains of most test specimens reached their 
Table 2 Effective stiffness and ductility in a negative loading direction obtained from test results.

\begin{tabular}{c|c|c|c|c}
\hline Specimens & $K_{e}(\mathrm{kN} / \mathrm{mm})$ & $\theta_{y}(\%)$ & $\theta_{u}(\%)$ & $\mu$ \\
\hline J-0 & 1.27 & 1.53 & 5.51 & 3.60 \\
\hline J-A & 1.27 & 1.53 & 5.51 & 3.60 \\
\hline J-CFRP & 1.34 & 1.58 & 5.77 & 3.65 \\
\hline J-H & 1.53 & 1.95 & 5.18 & 2.66 \\
\hline J-SJ1 & 1.21 & 1.77 & 6.51 & 3.68 \\
\hline J-SJ2 & 1.29 & 1.59 & 6.36 & 4.00 \\
\hline J-SJ3 & 1.30 & 1.63 & 6.26 & 3.84 \\
\hline
\end{tabular}

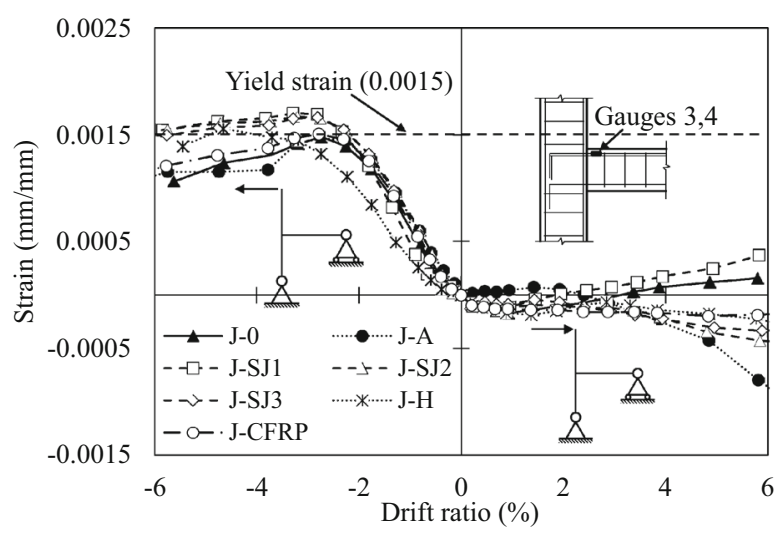

(a) Steel strain of top longitudinal re-bars in beams (gauges 3,4 )

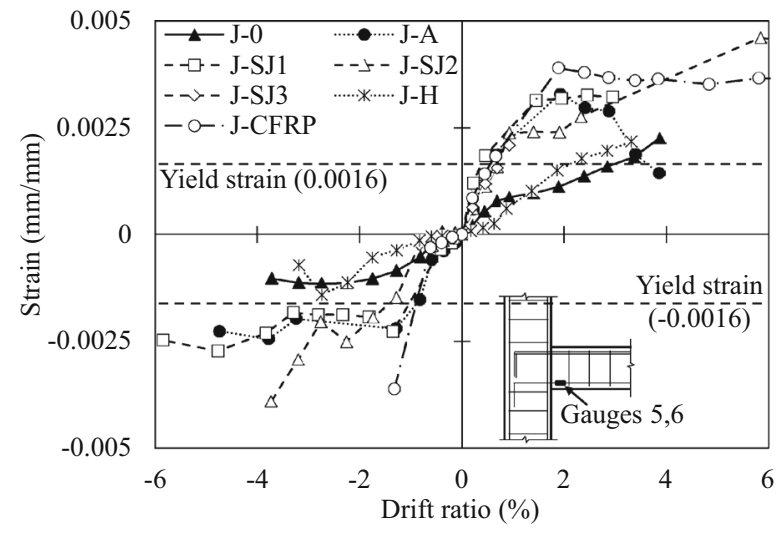

(b) Steel strain of bottom longitudinal re-bars in beams (gauges 5,6 )

Fig. 18 Strain profiles for longitudinal steel re-bars in beams.

yield strain of 0.0016 . After this stage, the retrofitted specimens J-A, J-CFRP, J-SJ1, and J-SJ2 exhibited significantly high tensile strain. In the negative direction, except for J-0, $\mathrm{J}-\mathrm{H}$, and $\mathrm{J}-\mathrm{SJ} 3$, the beam bottom longitudinal re-bars of the other retrofitted specimens yielded. In general, this data confirms the effectiveness of the proposed retrofit solutions and explains the ductile structural behavior observed in the test results.

\subsection{Stiffness Degradation}

In this study, the secant stiffness of the test specimens at each point of envelop curves was defined as the ratio between the lateral load and correlative lateral displacement.

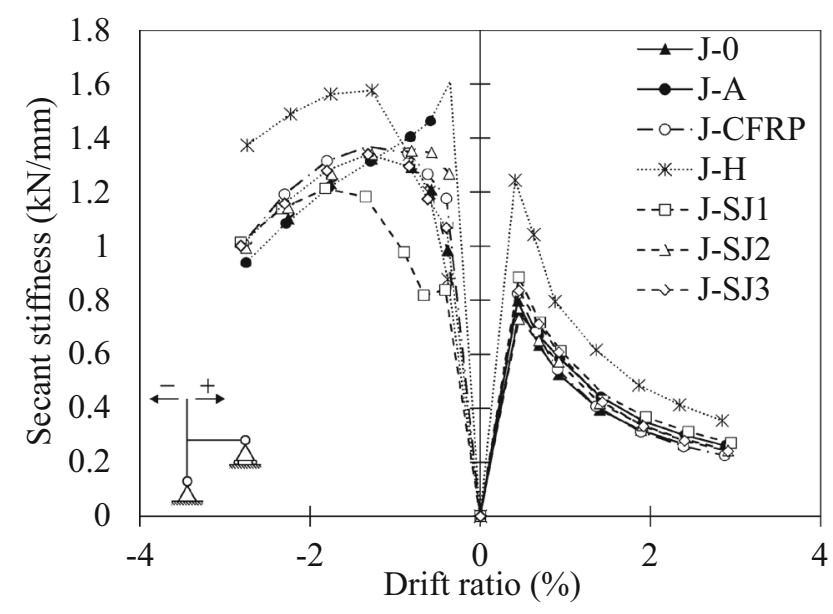

Fig. 19 Stiffness degradation curves.

Figure 19 shows the secant stiffness of the test specimens in the positive and negative directions. In general, the stiffness of the test specimens decreased with the increasing drift ratio; such degradation is attributed to the development of flexural and shear cracking in the beams and in the joint panel zones. As shown in the figure, in the negative direction, the retrofitted specimen J-H exhibited higher stiffness than that of the control specimen $\mathrm{J}-0$; this was attributed to the enlargement of the joints and the enhanced concrete confinement in the joints by using the steel haunch elements. At early drift ratio of $0.35 \%, \mathrm{~J}-\mathrm{A}$ also showed higher stiffness than that of J-0; however, after that, the stiffness of J-A suddenly decreased. Meanwhile, in the case of the other retrofitted specimens, at each loading cycle, the stiffness was almost the same as that of $\mathrm{J}-0$. In the positive direction, except for J-H, of which the stiffness was higher than that of $\mathrm{J}-0$, the other retrofitted specimens showed almost the same secant stiffness as that of $\mathrm{J}-0$.

\subsection{Dissipated Energy and Damping Ratio}

In this study, the dissipated energy at each loading cycle was calculated as the area enclosed by a hysteretic loop at that loading cycle. The cumulative dissipated energy was evaluated as the summation of areas calculated for each loading cycle. Figure 20a shows a comparison of the cumulative dissipated energy for the test specimens according to the various retrofit applications. In general, 

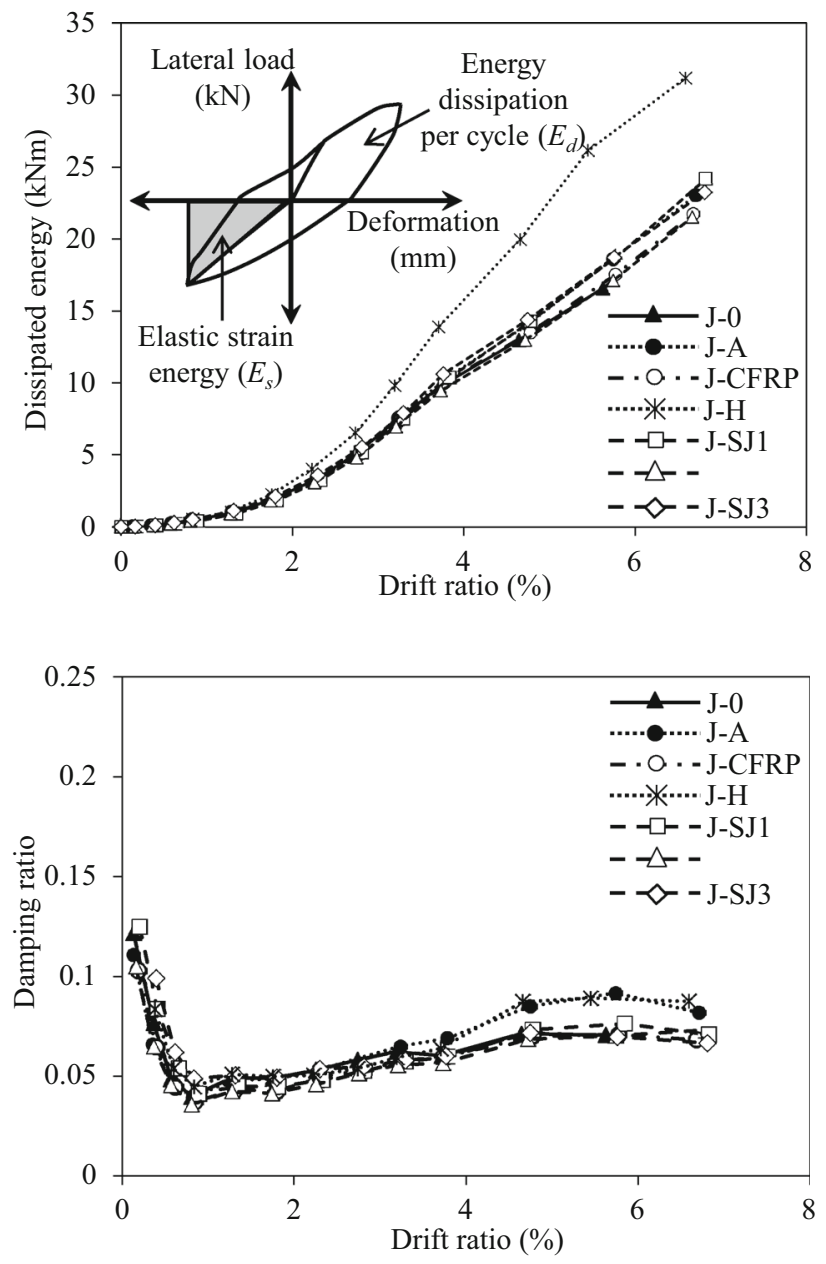

Fig. 20 Effects of various retrofit applications on dissipated energy and damping ratio.

except for $\mathrm{J}-\mathrm{H}$, the dissipated energy of most specimens showed the same trend and no significant difference was observed corresponding to the control specimen J-0. In the case of specimen $\mathrm{J}-\mathrm{H}$ retrofitted with haunch elements, for the drift ratios below $2 \%, \mathrm{~J}-\mathrm{H}$ dissipated almost the same energy as that of J-0. Then, the dissipated energy of $\mathrm{J}-\mathrm{H}$ was significantly greater than that of J-0 by approximately $45 \%$ at a drift ratio of $6.6 \%$.

The damping ratio $(\xi)$, which is one of the most important indices characterizing the dynamic response of the structures, is defined as $E_{d} / 4 \pi E_{s}$, where $E_{d}$ is the dissipated energy per cycle and $E_{s}$ is the elastic strain energy. Figure $20 \mathrm{~b}$ shows the damping ratio versus drift ratio of the test specimens for a negative loading direction. In general, as shown in the figure, the damping ratios of the retrofitted specimens were almost the same as that of the control specimen J-0. At the elastic state, the damping ratios were around $0.1-0.12$, then decreased to $0.036-0.044$ at a drift ratio of $0.77 \%$; beyond $0.77 \%$, the damping ratios slightly increased to $0.06-0.08$.

\section{Conclusions}

In this study, seven half-scale reinforced concrete beamcolumn joint specimens were designed to simulate the existing joints in concrete buildings constructed around 1980s in Korea. Six of the specimens were then retrofitted and tested under seismic loading only and one specimen was used as the control. The retrofit solutions applied in this test were head re-bars anchoring, CFRPs wrapping, haunch elements, and steel jacketing. Based on the results obtained in this study, the primary findings are as follows:

- In the retrofitted joints, except for J-CFRP, cracking damage (the number and the width of cracking) in the joint panel zone was significantly diminished by eye.

- The retrofit methods developed in this study including head re-bar anchoring, CFRP wrapping, haunch, and steel jacketing could partially enhance the strength and deformation capacity of the beam-column joints:

- In the joint retrofitted with haunch elements (J-H), the lateral load-carrying capacity was significantly increased up to approximately $53.3 \%$ but the deformation capacity was not enhanced. In addition, in specimen $\mathrm{J}-\mathrm{H}$, the plastic hinge region was relocated from the beam-column interface to inside the beam.

- Retrofitting with steel jackets, the deformation capacities and the lateral load-carrying capacities of specimens J-SJ1, J-SJ2, and J-SJ3 were improved up to approximately 10.7 and $18.1 \%$, respectively. However, steel jacketing and using steel haunch elements would be potential for corrosion and it is difficult to handle the heavy steel plates (Truong et al. 2017).

- The uses of CFRP wrapping and head re-bar anchoring did not effectively improve the strength and deformation capacity of the beam-column joints in this test. In the case of J-CFRP, the lateral loadcarrying capacity and the deformation capacity were slightly increased but the difference was not considerable. In contrast, the lateral load-carrying capacity and deformation capacity of specimen J-A were the same as those of J-0. Further research is needed for better understanding this behaviour.

- The stiffness of J-H was greater than that of J-0, while that of the other retrofitted specimens was almost the same as that of J-0. However, the stiffness degradation rates of the retrofitted specimens were similar to that of $\mathrm{J}-0$.

- The energy dissipation capacity of most specimens strengthened with head re-bars, CFRPs, and steel jackets showed almost the same trend as that of J-0, but the dissipated energy of the retrofitted specimen J-H continued to increase up to $45 \%$. On the contrary, the application of retrofit materials did not considerably affect the damping ratio. 


\section{Acknowledgements}

This research was supported by a Grant (NRF2014R1A1A2053499) from the National Research Foundation of Korea, Grant funded by the Korean Government.

\section{Open Access}

This article is distributed under the terms of the Creative Commons Attribution 4.0 International License (http:// creativecommons.org/licenses/by/4.0/), which permits un restricted use, distribution, and reproduction in any medium, provided you give appropriate credit to the original author(s) and the source, provide a link to the Creative Commons license, and indicate if changes were made.

\section{Appendix 1: Determination of Failure Modes of Beam-Column Joints}

According to the studies by Lee et al. (2009) and Teraoka et al. (1996), failure of the beam-column joints could be classified into three types: B failure, BJ failure, and $\mathrm{J}$ failure. Figure 1 presents the types of failure mode of the beam column joints. In the figure, B failure $\left(V_{c} / V_{u}>1.8\right)$ indicates flexural yielding of beams undergoing large inelastic deformation until ultimate rotational capacity without shear failure in joints; BJ failure $\left(1 \leq V_{c} / V_{u} \leq 1.8\right)$ indicates joint failure after initial yielding of beam reinforcement; and $\mathrm{J}$ failure $\left(V_{c} / V_{u}<1\right)$ indicates joint failure by shear force without yielding of beam reinforcement, where $V_{c}$ is the joint shear capacity and $V_{u}$ is the joint shear demand. In this study, the ratio $V_{c} / V_{u}$ of the control specimen (J-0) was 0.73 . The evaluation processes of the joint shear capacity $\left(V_{c}\right)$ and the joint shear demand $\left(V_{u}\right)$ of the concrete beam-column joints are presented in Appendix 2.

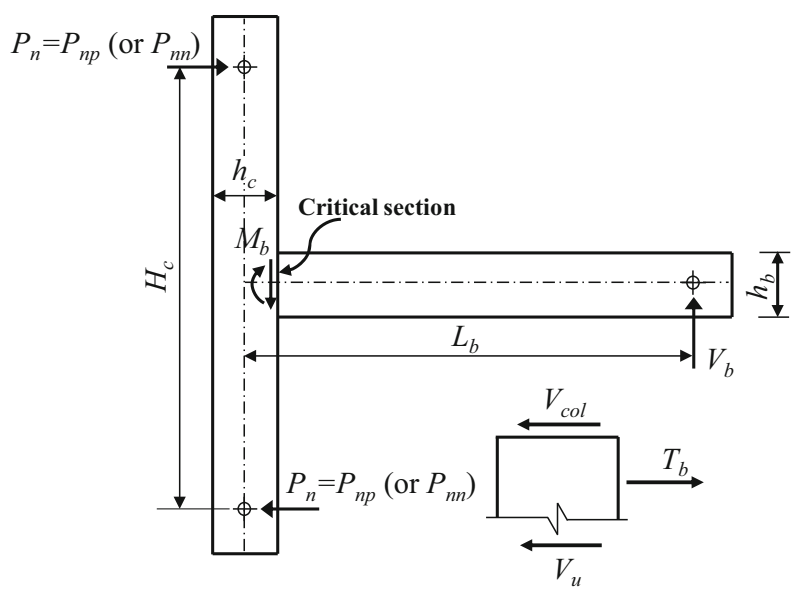

Fig. 21 Force equilibrium in beam-column joint.

\section{Appendix 2: Evaluation of Shear Strength of Beam-Column Joints}

In ACI 352R-02 (2002), the shear capacity of the joint $\left(V_{c}\right)$ is evaluated as follows in Eq. (1):

$$
V_{c}=0.083 \gamma \sqrt{f_{c}^{\prime}} b_{j} h_{c}
$$

where $f_{c}^{\prime}$ is the concrete compressive strength, and $b_{j}$ and $h_{c}$ are the effective joint width and the depth of the column in the direction of joint shear being considered, respectively. The joint shear demand $\left(V_{u}\right)$ is evaluated based on the beam yield mechanism to check the failure mechanism of the joints.

The nominal lateral load-carrying capacity of the columns $\left(P_{n}\right)$ is evaluated based on the assumption of yielding in beam reinforcement at the connection, as shown in Fig. 21.

$$
P_{n}=\frac{V_{b} \times L_{b}}{H_{c}}=\frac{M_{b}}{L_{b}-0.5 h_{c}} \times \frac{L_{b}}{H_{c}}
$$

where $P_{n}=P_{n p}$ or $P_{n n} ; V_{b}$ and $M_{b}$ are the shear force and moment developed by yielding of beam reinforcement, respectively; and $L_{b}$ and $H_{c}$ are the length of beams and columns, respectively.

\section{Appendix 3: Design Procedure of Haunch Elements through Retrofit of Beam-Column Joints}

Figure 22 shows the bending moment and shear diagrams of the beam-column joints after retrofitting with haunch elements according to the study by Chen (2006). In the figure, the bending moment $\left(M_{b c}\right)$ and shear in column $\left(V_{c}^{\prime}\right)$ at the interface of the joints were evaluated as follows in Eqs. (3) and (4), respectively.

$$
\begin{aligned}
& M_{b c}=M_{b(\max )}+(1-\beta) V_{b} L^{\prime}-\frac{h_{b} \beta V_{b}}{2 \tan \alpha} \\
& V_{c}^{\prime}=\left(1-\beta^{\prime}\right) V_{c}
\end{aligned}
$$

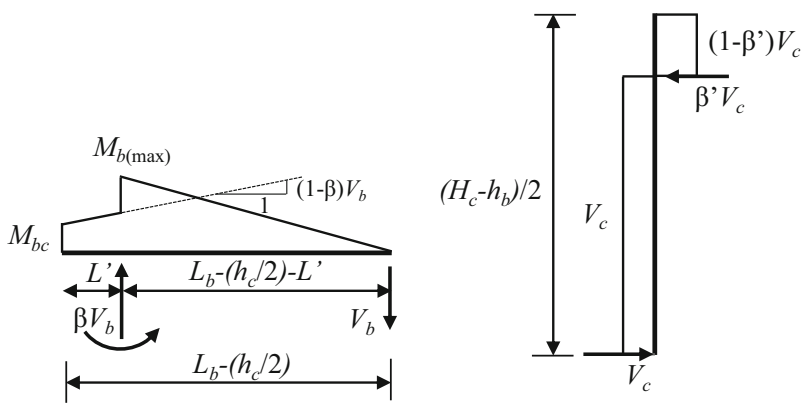

(a)

(b)

Fig. 22 Moment and shear diagrams after retrofitting with haunch elements (Chen 2006): a moment diagram in the beam and $\mathbf{b}$ shear diagram in the column. 
$\beta=\frac{b}{a}\left[\frac{6 L h_{b}+3 a h_{b}+6 b L+4 a b+\frac{2 I_{b} b^{3}}{I_{c} a H_{c}}+\frac{3 I_{b} H L_{b} b^{3}}{2 I_{c} a^{2} H_{c}}+\frac{3 I_{b} h_{c} H L_{b} b^{2}}{I_{c} a^{2} H_{c}}}{3 h_{b}+6 b h_{b}+4 b^{2}+\frac{12 E_{c} I_{b}}{2 K_{d} a \cos ^{2} \alpha}+\frac{6 I_{b} b^{2}}{a^{2} A_{c}}+\frac{2 I_{b} h_{c} b^{2}}{I_{c} a}+\frac{3 I_{b} h_{c} b^{2}}{I_{c} a^{2}}+\frac{3 I_{b} h_{c}^{2} b^{3}}{2 I_{c} a^{3}}}\right]$

$$
\begin{aligned}
& \beta^{\prime}=\beta\left(\frac{H_{c}}{L_{b} \tan \alpha}\right) \\
& K_{d}=\frac{E_{s} A_{d}}{L_{h}} \\
& L_{h}=\sqrt{a^{2}+b^{2}} \\
& H=H_{c}-h_{b}-2 b \\
& L=L_{b}-h_{c}-2 a
\end{aligned}
$$

where $M_{b(\max )}$ is the maximum bending moment in the beam; $V_{b}$ is the shear force in the beam; $\beta$ and $\beta^{\prime}$ are the factors expressing the effectiveness of the retrofit solution by determining the redistribution of the shear between the beam, column, and haunch elements in the joint; $a$ and $b$ are the projected length of the haunch elements on the beam and column, respectively; $h_{b}$ is the depth of the beam; $I_{b}$ and $I_{c}$ are the effective inertial moment of the beam and column, respectively; $\alpha$ is the angle between beam and diagonal haunch element; and $K_{d}$ is the stiffness of the haunch elements. The shear demand in the joint $\left(V_{u}\right)$ was evaluated by considering the beam yield mechanism.

\section{Appendix 4: Design Procedure of Head Re- bars, Steel Jackets, and CFRPs for Retrofit of Beam-Column Joints}

In this study, the retrofit purpose of exterior beam-column joints was to provide the joints with residual strength of half joint shear strength $\left(0.5 V_{c}\right)$. Thus, shear strength $\left(V_{s}\right)$ provided by retrofit materials should be greater than $0.5 V_{c}$.

$$
V_{s} \geq 0.5 V_{c}=0.0415 \gamma \sqrt{f_{c}^{\prime}} b_{j} h_{c}
$$

In the cases of specimens retrofitted with head re-bars, $V_{s}$ is calculated according to KCI (2012).

$$
V_{s}=A_{v} f_{y t}(\mu \sin \alpha+\cos \alpha)
$$

where $f_{y t}$ is the tensile strength of head re-bars, $A_{v}$ is the total area of head re-bars crossing an inclined shear plane, $\alpha$ is the angle between shear reinforcement and shear plane in the joint panel zone (in this study, $\alpha$ is assumed as $45^{\circ}$ ), and $\mu$ is the coefficient of friction $(=1.4$ for normalweight concrete placed monolithically).

In the cases of specimens retrofitted with steel jackets, $V_{s}$ is evaluated according to Eurocode 8-3 (2005). It is noted that only $50 \%$ of the steel yield strength of the jacket is used.

$$
V_{s}=0.5 h_{c} \frac{2 t_{s} b_{s}}{s} f_{y t, d}(\cot \theta+\cot \beta) \sin \beta
$$

where $t_{s}$ is the thickness of the steel jackets, $b_{s}$ is the width of the steel jackets, $s$ is the space of the steel jackets $\left(b_{s} / s=1\right.$, in the case of continuous steel plates), $\theta$ is the strut inclination angle, $\beta$ is the angle between the axis of the steel jackets and the axis of the member $\left(\beta=90^{\circ}\right.$, in the case of continuous steel plates), and $f_{y t, d}$ is the design yield strength of the steel jackets.

In the cases of specimens retrofitted with CFRPs, the contribution of CFRPs to the shear strength is evaluated according to ACI 440.2R-02 (2012).

$$
\begin{aligned}
& V_{s}=\frac{A_{f v} f_{f e}(\sin \alpha+\cos \alpha) d_{f}}{s_{f}} \\
& A_{f v}=\beta n t_{f} w_{f} \\
& f_{f e}=\varepsilon_{f e} E_{f} \\
& \varepsilon_{f e}=0.004 \leq 0.75 \varepsilon_{f u} \text { (for two-sided wrapping) }
\end{aligned}
$$

where $A_{f v}$ is the area of the CFRPs, $f_{f e}$ is the effective tensile stress of CFRPs at ultimate state, $d_{f}$ is the depth of the joint wrapped by CFRPs, $\alpha$ is the angle of CFRPs to the horizontal axis, $s_{f}$ is the space between two CFRPs plies, $\beta$ is the number of wrapping surfaces of members, $n$ is the number of CFRPs plies, $t_{f}$ is the thickness of the CFRP sheet, $w_{f}$ is the reduction factor ( $w_{f}$ is 0.85 for two-sided wrapping), $\varepsilon_{f e}$ is the effective strain level of CFRPs, $E_{f}$ is the elastic modulus of CFRPs, and $\varepsilon_{f u}$ is the ultimate strain of CFRPs.

\section{References}

ACI 352R. (2002). Recommendations for Design of beamcolumn connections in monolithic reinforced concrete structures. Farmington Hills, MI: American Concrete Institute.

ACI Committee 440. (2012). Guide for the design and construction of externally bonded FRP systems for strengthening concrete structures, ACI 440.2R-02. USA: American Concrete Institute.

ACI 374.2R-13. (2013). Guide for testing reinforced concrete structural elements under slowly applied simulated seismic loads. ACI Committee 374.

ACI 318-14. (2014). Building code requirement for structure concrete (ACI 318-14). Farmington Hills, MI, USA: American Concrete Institute.

Al-Tarazi, E. (2000). The major gulf of the Aqaba earthquake, 22 November 1995-Maximum intensity distribution. Natural Hazards, 22(1), 17-27.

Antonopoulos, C. P., \& Triantafillou, T. C. (2003). Experimental investigation of FRP-strengthening RC beam-column joints. Journal of Composites for Constructions, 7(1), $39-49$.

Architectural Institute of Korea (AIK). Reinforced Concrete Design Code and Commentary. 1982: 340 pp. (in Korean).

Bakis, C. E., Bank, L. C., Brown, V. L., Cosenza, E., Davalos, J. F., Lesko, J. J., et al. (2002). Fiber-reinforced polymer composites for construction-State-of-the-art review. Journal of Composites for Construction, 6(2), 73-87. 
Bansal, P. P., Kumar, M., \& Dar, M. A. (2016). Retrofitting of exterior RC beam-column joints using ferrocement jackets. Earthquakes and Structures, 10(2), 313-328.

Brena, S. F., \& McGuirk, G. N. (2013). Advances on the behavior characterization of FRP-anchored carbon fiberreinforced polymer (CFRP) sheets used to strengthen concrete frames. International Journal of Concrete Structures and Materials, 7(1), 3-16.

Campione, G., Cavaleri, L., \& Papia, M. (2015). Flexural response of external R.C. beam-column joints externally strengthened with steel cages. Engineering Structures, 104, 51-64.

Chen, T.-H. (2006). Development of a low invasive seismic retrofit solution for under-designed frame systems based on a metallic haunch. Master Thesis, University of Canterbury, Christchurch, New Zealand.

Del Vecchio, C., Di Ludovico, M., Balsamo, A., Prota, A., Manfredi, G., \& Dolce, M. (2014). Experimental investigation of exterior RC beam-column joints retrofitted with FRP system. Journal of Composites for Construction, 18(4), 04014002.

Del Vecchio, C., Di Ludovico, M., Prota, A., \& Manfredi, G. (2015). Analytical model and design approach for FRP strengthening of non-conforming RC corner beam-column joints. Engineering Structures, 87, 8-20.

Del Vecchio, C., Di Ludovico, M., Prota, A., \& Manfredi, G. (2016). Modelling beam-column joints and FRP strengthening in the seismic performance assessment of RC existing frames. Composites Structures, 142, 107-116.

El-Amoury, T., \& Ghobarah, A. (2002). Seismic rehabilitation of beam-column joint using GFRP sheets. Engineering Structures, 24, 1397-1407.

Engindeniz, M., Kahn, L. F., \& Zureick, A.-H. (2005). Repair and strengthening of reinforced concrete beam-column joints: State of the art. ACI Structural Journal, 102(2), 1-14.

Eurocode 8. (2005). Design of structures for earthquake resistance-Part 3: assessment and retrofitting of buildings, EN 1998-3-2005. Brussels, Belgium: European Committee for Standardization, CEN.

Genesio, G. (2012). Seismic assessment of RC exterior beamcolumn joint and retrofit with haunches using post-installed anchors. PhD Dissertation, Institut für Werkstoffe im Bauwesen der Universität Stuttgart, Germany.

Grelle, S. V., \& Sneed, L. H. (2013). Review of anchorage systems for externally bonded FRP laminates. International Journal of Concrete Structures and Materials, 7(1), 17-33.

Kanamori, H., \& Kikuchi, M. (1993). The 1992 Nicaragua earthquake: A slow tsunami earthquake associated with subducted sediments. Nature, 361, 714-716.

KCI 2012. (2012). Design code of concrete structure. Seoul: Korean Concrete Institute.

KS B 0814. (2001). Method of tensile test for metallic materials. Seoul: Korean Standard Information Center.

KS B 0802. (2013). Method of tensile test for metallic materials. Seoul: Korean Standard Information Center.

KS F 2405. (2010). Standard test method for compressive strength of concrete. Seoul: Korean Standard Information Center.
Lee, J. Y., Kim, J. Y., \& Oh, G. J. (2009). Strength deterioration of reinforced concrete beam-column joints subjected to cyclic loading. Engineering Structures, 31(9), 2070-2085.

Liang, X.-W., Wang, Y.-J., Tao, Y., \& Deng, M.-K. (2016). Seismic performance of fiber-reinforced concrete interior beam-column joints. Engineering Structures, 126, 432-445.

Mahmoud, M. H., Afefy, H. M., Kassem, N. M., \& Fawzy, T. M. (2014). Strengthening of defected beam-column joints using CFRP. Journal of Advanced Research, 5, 67-77.

Ozbakkaloglu, T., \& Saatcioglu, M. (2009). Tensile behavior of FRP anchors in concrete. ASCE Journal of Composites for Construction, 13(2), 82-92.

Pampanin, S., Calvin, G. M., \& Moratti, M. (2002). Seismic behaviour of R.C. beam-column joints designed for gravity loads. $12^{\text {th }}$ European Conference on Earthquake Engineering. London, England.

Pampanin, S., Christopoulos, C., \& Chen, T. H. (2006). Development and validation of a metallic haunch seismic retrofit system for existing under-designed RC frame buildings. Earthquakes Engineering \& Structural Dynamics, 35, 1739-1766.

Pantazopoulou, S., Tastani, S., Thermou, G., Triantafillou, T., Monti, G., Bournas, D., et al. (2016). Background to the European seismic design provisions for retrofitting RC elements using FRP materials. Structural Concrete, 17(2), 194-219.

Pantelides, C. P., Clyde, C., \& Reaveley, L. D. (2002). Performance-based evaluation of reinforced concrete building exterior joints for seismic excitation. Earthquake Spectra, 18(3), 449-480.

Pantelides, C. P., Hansen, J., Nadauld, J., \& Reaveley, L. D. (2008). Assessment of RC building exterior joints with substandard details. PEER Report No. 2002/18, Pacific Earthquake Engineering Research Centre, College of Engineering, University of California, Berkeley.

Petrone, F., Shan, L., \& Kunnath, S. K. (2016). Modeling of RC frame buildings for progressive collapse analysis. International Journal of Concrete Structures and Materials, 10(1), $1-13$.

Priestley, M. J. N. (1997). Displacement-based seismic assessment of reinforced concrete buildings. Journal of Earthquake Engineering, 1(1), 157-192.

Quintero-Febres, C. G., \& Wight, J. K. (2001). Experimental study of reinforced concrete interior wide beam-column connections subjected to lateral loading. ACI Structural Journal, 98(4), 572-582.

Rashidian, O., Reza, A., Ahmadi, R., \& Nav, F. M. (2016). Progressive collapse of exterior reinforced concrete beamcolumn sub-assemblages: Considering the effects of a transverse frame. International Journal of Concrete Structures and Materials, 10(4), 479-497.

Realfonzo, R., Napoli, A., \& Pinilla, J. G. R. (2014). Cyclic behavior of RC beam-column joints strengthened with FRP systems. Construction and Building Materials, 54, 282-297.

Ronagh, H. R., \& Baji, H. (2014). On the FE modelling of FRPretrofitted beam-column subassemblies. International 
Journal of Concrete Structures and Materials, 8(2), 141-155.

Ruiz-Pinilla, J. G., Pallares, F. J., Gimenez, E., \& Calderon, P. A. (2014). Experimental tests on retrofitted RC beam-column joints underdesigned to seismic loads. General approach. Engineering Structures, 59, 702-714.

Santersiero, G., \& Masi, A. (2015). Seismic performance of RC beam-column joints retrofitted with steel dissipation jackets. Engineering Structures, 85, 95-106.

Seismic Simulation Test Center of Pusan National University, Development of Technologies for Improvement of Seismic Performance on the Existing Low-rise Buildings, National Emergency Management Agency, 2011, 585 pp. (in Korean).

Shafaei, J., Hosseini, A., \& Marafet, M. S. (2014). Seismic retrofit of external $\mathrm{RC}$ beam-column joints by joint enlargement using prestressed steel angles. Engineering Structures, 81, 265-288.

Sharma, A., Genesio, G., Reddy, G. R., Eligehausen, R., Pampanin, S., \& Vaze, K. K. (2010). Experimental investigations on seismic retrofitting of reinforced concrete beam-column joints. 14th Symposium on Earthquake Engineering. Roorkee: Indian Institute of Technology.
Sharma, A., Reddy, G. R., Eligehausen, R., Genesio, G., \& Pampanin, S. (2014). Seismic response of reinforced concrete frames with haunch retrofit solution. ACI Structural Journal, 111(3), 673-684.

Singh, V., Bansal, P. P., Kumar, M., \& Kaushik, S. K. (2014). Experimental studies on strength and ductility of CFRP jacketed reinforced concrete beam-column joints. Construction and Building Materials, 55, 194-201.

Suarez, G., Pardo, M., Dominguez, J., Ponce, L., Walter, M., Boschini, I., et al. (1995). The Limon, Costa Rica earthquake of April 22, 1991: Back arc thrusting and collisional tectonics in a subduction environment. Tectonics, 14(2), $518-530$.

Teraoka, M., Kanoh, Y., Sasaki, S., \& Hayashi, K. (1996). An estimation of ductility in interior beam-column subassemblages of reinforced concrete frames. Journal-Society of Materials Science Japan, 45, 1033-1041.

Truong, G. T., Kim, J.-C., \& Choi, K.-K. (2017). Seismic performance of reinforced concrete columns retrofitted by various methods. Engineering Structures, 134, 217-235.

Tsonos, A.-D. (2010). Performance enhancement of R/C building columns and beam-column joints through shotcrete jacketing. Engineering Structures, 32, 726-740. 